\title{
Laboreal
}

Volume $10 \mathrm{~N}^{\circ} 2$ | 2014

Análise ergonómica do trabalho e formação - Parte II

\section{La salud y la seguridad de los alumnos en centros de capacitación profesional: enfoques, representaciones y género}

A saúde e a segurança dos estudantes num centro de formação profissional:

Abordagens, representações e género

La santé et la sécurité des élèves en centre de formation professionnelle:

approches, représentations et genre

Student health and safety in a vocational training center: Approaches,

representations and gender

\section{Céline Chatigny y Jessica Riel}

\section{OpenEdition}

Journals

Edición electrónica

URL: http://journals.openedition.org/laboreal/4881

DOI: 10.4000/laboreal.4881

ISSN: 1646-5237

Editor

Universidade do Porto

Referencia electrónica

Céline Chatigny y Jessica Riel, « La salud y la seguridad de los alumnos en centros de capacitación profesional: enfoques, representaciones y género », Laboreal [En línea], Volume 10 N² | 2014,

Publicado el 01 diciembre 2014, consultado el 07 octubre 2019. URL : http://journals.openedition.org/ laboreal/4881; DOI : 10.4000/laboreal.4881

Este documento fue generado automáticamente el 7 octubre 2019.

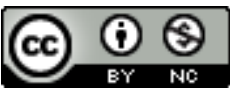

Laboreal está licenciado com uma Licença Creative Commons - Atribuição-NãoComercial 4.0 Internacional. 


\section{La salud y la seguridad de los} alumnos en centros de capacitación profesional: enfoques, representaciones y género

A saúde e a segurança dos estudantes num centro de formação profissional: Abordagens, representações e género

La santé et la sécurité des élèves en centre de formation professionnelle: approches, représentations et genre

Student health and safety in a vocational training center: Approaches, representations and gender

\section{Céline Chatigny y Jessica Riel}

\section{NOTA DEL EDITOR}

http://dx.doi.org/10.15667/laborealx0214cc1

Manuscrito recibido en: Diciembro 2013

Aceptado tras peritaje: Agosto 2014

Agradecemos muy sinceramente a los participantes y a los asistentes de investigación Vanessa Couture, Priscille Hastey et Livann Nadon, así como a los organismos que han otorgado subsidios: Fonds québécois de recherche sur la société et la culture, Institut de recherche Robert Sauvé en santé et en sécurité du travail, y el Service aux collectivités de l'Université du Québec à Montréal -Fondo quebequense de investigación sobre la sociedad y la cultura, Instituto de investigación Robert Sauvé en salud y seguridad del trabajo, Servicio a las colectividades de la Universidad de Quebec en Montreal. 


\section{PROBLEMÁTICA}

\subsection{El sector de la formación profesional (FP) en entorno escolar en Quebec}

1 Este sector de la enseñanza ofrece más de 170 programas de estudio en 200 centros de formación profesional (CFP), tales como, conducción de maquinarias de construcción, ebanistería, secretariado, o ventas y asesoramiento. Algunos de los CFP están especializados, por ejemplo en mecánica de equipamientos de motor o en cuidados de la salud, mientras que otros ofrecen una diversidad de programas. Una parte importante de la enseñanza y el aprendizaje se realiza en talleres provistos de diversos tipos de equipos, útiles y herramientas, en los que los docentes y alumnos trabajan, circulan y dialogan. En algunos casos, como en el de los oficios de cuidados estéticos, se reciben clientes, aunque también es frecuente que los alumnos actúen como clientes ante sus colegas para poder practicar cortes de cabello, peinado (brushing) y coloración. Se trata entonces de contextos y entornos diferentes, que implican diversos riesgos y actores. La seguridad y salud en el trabajo (SST) es fundamental en las actividades de enseñanza y aprendizaje. Las prescripciones relativas a la SST provienen de todas partes: del Ministère de l'Éducation, du Loisir et du Sport (MELS) -Ministerio de la Educación y del tiempo libre-, de la Commission de la santé et de la sécurité (CSST) Comisión de la Salud y de la Seguridad-, de la Commission scolaire -Comisión escolar-, del Centre de Formation Professionnel (CFP) -Centro de formación profesional-, de los miembros del equipo docente.

2 La población de alumnos del sector de la FP es heterogénea. Algunos de ellos han seguido una trayectoria escolar continua, pero la mayoría efectúa un retorno a los estudios después de un período de abandono escolar, de trabajo, de desempleo o de inmigración. Por ende, los grupos son generalmente heterogéneos en cuanto a la edad y a la experiencia. Los menores de 20 años representaban el 17,7\% en 2005 y fueron objeto de un plan de acción para aumentar su presencia; en 2008, la taza alcanzaba el 30\% (Bédard, 2003 citado por Grossmann et al., 2014). Algunos programas de estudio atraen una población mixta en cuanto al sexo y a la edad, como por ejemplo el programa de contabilidad, pero la mayor parte de ellos atraen sobre todo mujeres, como en el caso del sector de cuidados, u hombres, como el sector de construcción. En Quebec, la distribución de mujeres y hombres entre los alumnos en formación profesional es de $44 \%$ y 56\% respectivamente (Gouvernement du Québec, 2010, p. 15). Es sabido que los oficios están fuertemente sexuados y que esta división social del trabajo se refleja en la SST de hombres y mujeres (Messing et al., 1998; Messing \& Chatigny, 2004; Riel, 2009; Riel \& Messing, 2011; Seifert \& Messing, 2007; entre otros).

\subsection{La situación de las mujeres con trayectoria en empleos predominantemente masculinos}

Los oficios tradicionalmente femeninos [1] se caracterizan en general por incluir tareas repetitivas, posturas estáticas prolongadas y un estrecho margen de maniobra, mientas que los oficios tradicionalmente masculinos implican a menudo un mayor esfuerzo, desplazamientos y amplios márgenes de maniobra. Un análisis de los datos arrojados por la encuesta EQCOTESST [ $\left.{ }^{2}\right]$ confirma que las mujeres se ven más afectadas que los 
hombres por problemas musculo esqueléticos (Stock et al., 2013, 2008; Vézina et al., 2011). Los resultados muestran, en cambio, que los hombres están más expuestos a las limitaciones físicas que las mujeres -salvo en lo que se refiere a los gestos repetitivosligadas al trabajo en ordenador y a la postura de sentado prolongada; mientras que las mujeres están más expuestas al conjunto de las limitaciones organizacionales medidas. Estos autores constatan también una correlación entre los Trastornos MúsculoEsqueléticos (TME) y los factores psicosociales. Las limitaciones organizacionales y las fuentes de violencia en los servicios en que las mujeres son mayoría, así como el esfuerzo de conciliar trabajo y familia, afectan su salud física y psicológica (Prévost \& Messing, 2001). Las tareas realizadas por las mujeres son a menudo percibidas como más fáciles, asociadas con habilidades que se presumen intrínsecamente femeninas y menos problemáticas para la salud; las exigencias cognitivas, emocionales y físicas de su trabajo son subestimadas (Seifert \& Messing, 2007; Chatigny et al., 2005; Messing \& Seifert, 2001; McDiarmid \& Gucer, 2001; entre otros). Las mujeres que ocupan un empleo tradicionalmente masculino están a menudo más expuestas que sus colegas masculinos, debido a que la disposición y los equipamientos suelen ser inadecuados. Además, ellas se enfrentan, todavía actualmente, a la discriminación y al acoso sexual y psicológico (Chatigny et al., 2011; Pratte, 2008; Couture et al., 2004; Ministère du travail, 2001).

\subsection{Situaciones de riesgo para los alumnos en formación profesional (FP)}

4 Los alumnos del sector de la FP son susceptibles de estar expuestos en parte al mismo tipo de situaciones identificadas más arriba. En los talleres y en las prácticas de estudio, pueden verse expuestos a diversos riesgos como consecuencia de la actividad ejercida, de la falta de experiencia y de los contextos, tal como lo han revelado Girard et al. (2006) al cabo de un estudio exploratorio en un CFP, con alumnos (masculinos) en oficios relacionados con la industria automotriz. Los investigadores han encontrado una tasa elevada de accidentes entre los alumnos (22\%) de Mantenimiento de equipos motorizados, en el transcurso de un período de cuatro meses. La mayor parte de los accidentes ocurrían en mecánica automotriz y carrocería $(83,3 \%=60 / 72$ eventos $)$ y afectaban sobre todo las manos. Un cuestionario respondido por los alumnos (123) reveló también dolores de espalda y de cabeza, fatiga y problemas cutáneos en relación con las actividades en talleres. Los autores concluían que era necesario documentar dicho fenómeno, respecto de la mayor cantidad de accidentes en los trabajadores jóvenes de 16 a 24 años (datos de la CSST - Comisión de salud y seguridad en el trabajoy ESS-98 -Encuesta Social y de Salud-, Ledoux \& Laberge, 2006). Este tipo de estudios no ha sido realizado sobre las poblaciones femeninas en CPF. No obstante, Pratte (2008) constató que las situaciones de práctica de estudios pueden exponer a las alumnas de formaciones no tradicionales a riesgos psicosociales importantes: discriminación para acceder a una práctica y para realizar tareas previstas, acoso psicológico y sexual, agresiones verbales y físicas. Por otra parte, en los jóvenes en curso de formación en oficios semi especializados orientados al empleo, Laberge (2011) ha podido observar características de exposición diferentes según sean oficios elegidos por mujeres o por hombres. 
5 En el transcurso de su formación, los alumnos deben desarrollar las competencias requeridas por el Ministerio de Educación (MELS) para integrarse al mercado de trabajo. La mayor parte de los programas de estudio incluyen un módulo de enseñanza de SST. Otros aspectos de la SST están integrados a módulos de enseñanza de competencias específicas para cada oficio. En general son presentados como reglas y procedimientos que deben aplicarse, como actitudes a desarrollar. Antes de la concepción de los programas de estudios, el MELS realiza un Análisis del ejercicio profesional (hasta hace poco llamado Análisis de la situación de trabajo), con la colaboración de la Comisión de salud y seguridad en el trabajo (CSST) y de expertos en el oficio, practicantes y docentes. Si bien la ley (LSST, L.R.Q., S-2.1) establece la responsabilidad compartida entre empleadores y trabajadores, la cultura de prevención dominante en diversos medios (en empresas pequeñas y medianas) apuesta a la responsabilidad individual. En consecuencia, a menudo se descuidan tanto la integración de la SST en el aprendizaje de las tareas como la prevención en origen. (Delgoulet \& Vidal-Gomel, 2013; Ouellet, 2009; Ouellet \& Vézina, 2005; Chatigny et al., 2005). Pocas formaciones ofrecen herramientas para identificar y prevenir los riesgos, y para desarrollar el saber hacer preventivo y eficiente, indispensable para alcanzar los objetivos de producción sin descuidar la protección de la salud (por ejemplo, desplazar a un paciente con un colega para reducir la carga de trabajo) (Ouellet \& Vézina, 2009).

6 Abocándose al análisis de la construcción de experiencia en salud ocupacional en hombres jóvenes, ubicados entre el liceo profesional y las pasantías en empresas en Francia, Frigul y Thébaud-Mony (2010) constataron que la formación escolar no ofrece una buena preparación para afrontar las cuestiones relacionadas con la SST en el mercado de trabajo. El estudio longitudinal fue realizado tomando tres clases, y a continuación un grupo de alumnos con el objeto de identificar sus recorridos de formación y de inserción. Tres son los resultados que más llaman nuestra atención: los autores notan un déficit del papel central de la escuela en el aprendizaje de los riesgos profesionales; en contextos de inserción precaria e individualizada, la formación no aporta ningún saber hacer útil para hacer frente a las situaciones de trabajo concretas; 6 jóvenes sobre 27 sufren un accidente de trabajo durante de los dos primeros años desde su ingreso laboral. Un estudio en Quebec acerca de situaciones de compañerismo en el medio laboral había señalado también dificultades para transferir las estrategias de prudencia aprendidas en el medio escolar, con relación a las culturas SST y a la débil integración de la SST en la recepción y la formación (Chatigny et al., 2000).

\subsection{Un contexto social favorable para el estudio de la SST en CFP}

7 La firma del Protocolo de Quebec [3] en 2003 y de un acuerdo administrativo entre la CSST y el MELS en 2005 (Commission de la santé et de la sécurité du travail du Québec, 2005) ha promovido desarrollos en los CFP. Este acuerdo apunta a la integración de la SST en la formación profesional y técnica con el fin de reducir la elevada tasa de accidentes entre los jóvenes trabajadores [ $\left.{ }^{4}\right]$. En ellos se enuncian cuatro principios:

- las competencias en SST asociadas con cada una de las etapas de realización de un trabajo se integrarán a la formación conforme avance el aprendizaje del oficio;

- el dominio de los conocimientos requeridos y de las prácticas recomendadas en materia de SST se evaluarán de manera integral con la formación; 
- la formación propiamente dicha como entorno adoptará prácticas ejemplares en materia de salud y seguridad para el alumno y favorecerá su puesta en práctica a través de políticas o códigos de procedimientos;

- el material, el equipamiento y el medioambiente responderán a las normas y reglas reconocidas en materia de SST. hasta 2013, al principio con el apoyo de «orientadores de prevención para la juventud», y más tarde con la intervención de inspectores que han librado constataciones de infracción e impuesto plazos para corregirlas. Las intervenciones de la CSST apuntan a los programas de estudio que preparan para oficios de los sectores de empleo "prioritarios", así definidos con relación a la frecuencia y gravedad de los accidentes declarados y reconocidos por dicha Comisión. Son empleos de sectores primarios y secundarios, en parte mixtos pero sobre todo tradicionalmente masculinos. Las restantes empresas u organizaciones de los sectores secundarios y terciarios, sobre todo mixtos o tradicionalmente femeninos, no son sometidas a todas las obligaciones legislativas, en particular a las de tener una comisión paritaria de SST y un representante de prevención. De esta manera, las intervenciones de la CSST en los centros de formación apuntan prioritariamente a los oficios reconocidos como de alto riesgo de accidentes, relacionados con la utilización de máquinas y equipamiento pesado.

9 En nuestras investigaciones anteriores, habíamos estudiado las problemáticas de aprendizaje de la SST en situaciones de formación puntuales y de aprendizajes oportunistas en el transcurso de actividades de producción. En la presente investigación, el contexto escolar ha suscitado nuevas preguntas. ¿Cuáles son las representaciones que tienen los actores de la SST en la escuela acerca de la SST de los alumnos? ¿Cuáles son el lugar y los enfoques de la SST en la referencia de competencias del oficio y en la enseñanza? ¿Cómo influencian la formación y las condiciones de aprendizaje las representaciones, la salud y las competencias de los alumnos acorde a los programas de estudio? ¿Qué papel juegan la escuela, sus actores clave y, por consiguiente, también los alumnos?

\subsection{Los objetivos}

10 La investigación-acción realizada buscaba identificar las problemáticas de SST en centros de formación profesional (CFP) en relación con cuatro dimensiones determinadas en colaboración con los actores sociales involucrados, así como en función de la revisión bibliográfica (figura 1). Los objetivos específicos buscados eran: 1 . Identificar los aspectos de SST en juego, los actores clave, sus dinámicas y necesidades; 2. precisar los contextos de enseñanza y de aprendizaje, los riesgos de SST para capacitadores y alumnos; 3. Analizar la actividad de los docentes y alumnos en contextos diferentes; 4. Desarrollar una red de actores sociales involucrados en la SST en FP. Esta investigación es exploratoria y no pretende, por lo tanto, trazar un cuadro completo de la situación sino más bien detectar los aspectos a considerar en las intervenciones e investigaciones futuras.

11 Los objetivos del artículo se vinculan más con el segundo objetivo, y particularmente con las problemáticas de la salud y seguridad de los alumnos: las representaciones de la SST de los alumnos según los grupos de actores entrevistados, las condiciones de

Laboreal, Volume $10 \mathrm{~N}^{\circ} 2$ | 2014 
aprendizaje y sus efectos sobre la salud de los alumnos, y el enfoque de la SST en los documentos programáticos de enseñanza de los oficios de las formaciones PEL y ESA.

Figura 1. Dimensiones de la SST estudiadas en esta investigación y aspecto presentado en este artículo (2).

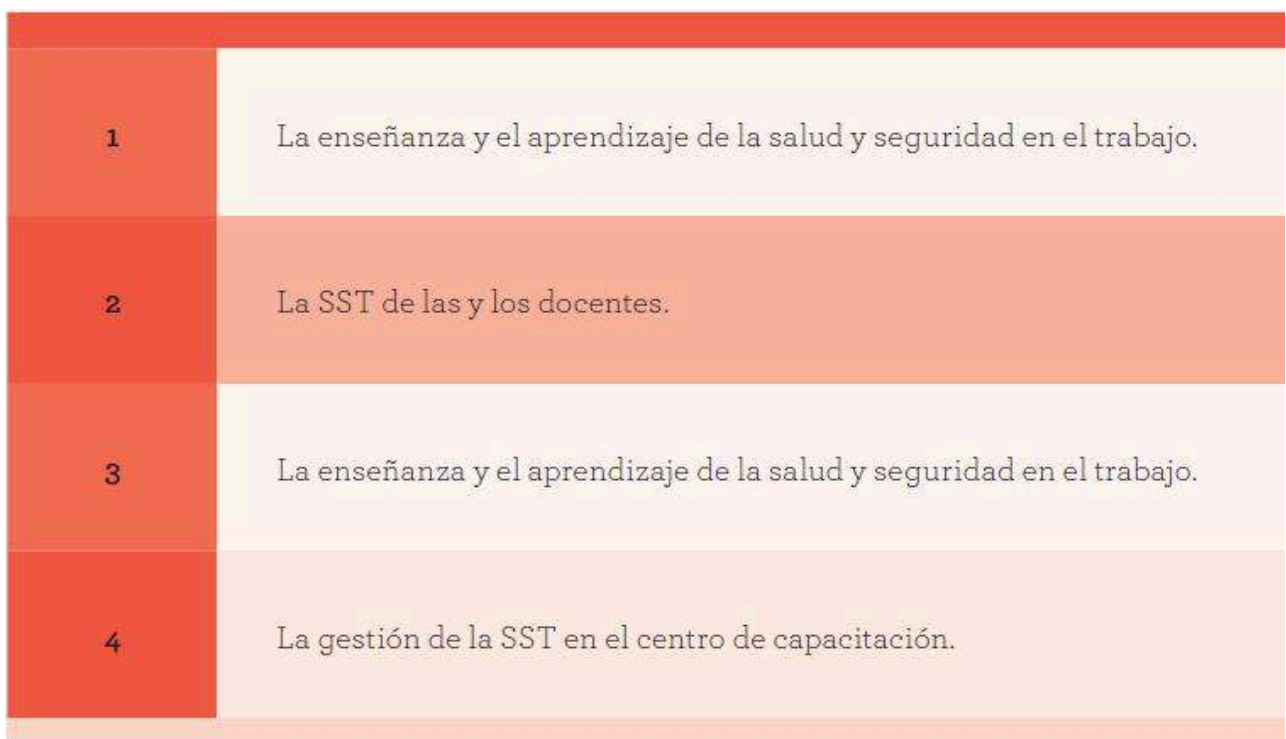

\section{MÉTODOS}

Nuestro enfoque se basa en el análisis ergonómico de la actividad de trabajo desde una perspectiva abarcadora. Este punto de vista distingue el trabajo prescripto del trabajo real y busca los factores determinantes del trabajo como actividad, a los que utiliza como apoyo para mejorar las condiciones de realización del trabajo así como la salud de quienes lo realizan (St-Vincent et al., 2011). Nuestra problemática nos ha conducido a explorar las situaciones de trabajo y de aprendizaje, las representaciones para la acción y los factores contextuales determinantes (Teiger, 1993). Los trabajos que tratan sobre el desarrollo de didácticas profesionales basadas en un enfoque ergonómico (entre los cuales, Vidal-Gomel et al., 2014) también han alimentado nuestra comprensión de la problemática. Por último, hemos mantenido, a lo largo de todo el proceso, un análisis diferenciado según el género, para poder comprender y sostener adecuadamente las situaciones específicas que enfrentan hombres y mujeres (Messing \& Stelmann, 2006; Messing \& Chatigny, 2004; Messing, 1999, entre otros). La cuestión del género se planteó de entrada, no solamente a los investigadores sino también a los actores sociales involucrados, ante la constatación de las diferentes exigencias propias de los oficios tradicionalmente femeninos y masculinos, y de los obstáculos identificados en el caso de las alumnas en programas de estudio predominantemente masculinos.

\subsection{La demanda social y la participación como modalidades del proceso ergonómico}

13 La participación y la intervención son centrales en nuestra tarea de investigaciónacción (St-Vincent et al., 2011). Los actores que han participado del comité de seguimiento de la investigación, desde el análisis del pedido hasta la elaboración de 
pautas de trabajo, son: la Centrale des Syndicats du Québec (CSQ) -Central de sindicatos de Quebec- que fue el primer solicitante, la Commission de la santé et de la sécurité du travail (CSST) y el Ministère de l'éducation, du loisir et des sports (MELS) que apoyaron la solicitud de financiamiento, el Institut de Recherche Robert Sauvé en Santé et en Sécurité du Travail (IRSST) -Instituto de Investigación Robert Sauvé en Salud y Seguridad del Trabajo- que financió la realización y proveyó una fuente para la coordinación de los trabajos del comité, y después la Fédération des Commissions Scolaires du Québec (FCSQ) -Federación de la Comisiones de Salud Pública- y el Institut National de Santé Publique du Québec (INSPQ) -Instituto Nacional de salud pública- que se sumaron al equipo. También hemos consultado con docentes y autoridades escolares para definir métodos y pautas de trabajo, tanto en el inicio como al final de la investigación. Otros dos comités de seguimiento han jugado un papel activo en el transcurso de la investigación: un comité interno del CFP correspondiente al comité de salud y seguridad del CFP et un comité de trabajo con el Servicio de colectividades de la UQAM y la sección Trabajo y salud de los capacitadores y capacitadoras de la CSQ, que también ha financiado una parte de la investigación.

\subsection{La selección del CFP, de los programas de estudios y de los participantes}

El CFP que participó fue designado en colaboración con la CSQ según los siguientes criterios: interés de la dirección, el sindicato y los docentes por participar en el desarrollo de conocimientos y prácticas en SST; oferta diversificada de programas de estudio que implicaran diferentes exigencias en los planos de la enseñanza, el aprendizaje, los contextos, e impactos potenciales sobre la salud; características variadas de los capacitadores y de los alumnos (sexo y edad, antigüedad y posición del empleo en los docentes). A través de reuniones en el CFP se pudo validar el interés de la dirección, del sindicato local, de la comisión paritaria de SST del establecimiento, y de los docentes coordinadores de grupos. Si bien la dirección expresó sus temores en cuanto al impacto eventual de los resultados, también veía en ellos la posibilidad de poner en valor las particularidades poco conocidas de este sector de la enseñanza y sus esfuerzos en materia de SST. Preocupaciones relacionadas con todas las temáticas de SST, con un mayor interés en el aprendizaje de la SST por parte de los alumnos, en particular de las alumnas en carreras no tradicionales. Los encuentros condujeron a la selección de programas de estudio que representaran realidades diferentes, desde el punto de vista de las personas, tipos de tareas y entornos: Peluquería y Decoración de interiores, predominantemente femeninas (de aquí en adelante: PEL y DEC) y Electromecánica de sistemas automatizados, con predominio masculino (de aquí en adelante: ESA). Además, se han recolectado datos en otros programas de estudio, tales como, contabilidad, dibujo técnico, estética, mecánica automotriz, refrigeración, secretariado, soldadura y montaje, venta de viajes.

El total de 76 participantes se compone de: 37 capacitadores ( 25 provenientes de los 3 programas designados; 12 hombres, 13 mujeres), 20 alumnos (19 provenientes de los programas de PEL y ESA: 11 mujeres, 8 hombres), 11 representantes de la dirección y de los servicios profesionales (6 representantes de la dirección, 3 asesores pedagógicos, 2 encargados de materiales) y 8 participantes externos al CFP (organismos asociados, mujer egresada de una formación). 


\subsection{Las etapas y los métodos de recolección y de análisis de datos} La triangulación de los métodos y de las fuentes de datos ha sido realizada con la ayuda de análisis de documentos, entrevistas individuales y colectivas, observaciones y un cuestionario auto administrado. Esto ha permitido validar la coherencia de los datos. El cuadro 1 resume los métodos relativos a entrevistas y observaciones, en cada grupo de participantes (alumnos, docentes, otros participantes del CFP, y participantes externos al CFP).

Las fuentes documentales provinieron de las organizaciones y del CFP involucrados. Se han recogido datos sobre la organización del sector de la formación profesional, las características de los alumnos y los docentes, los enfoques pedagógicos, las lesiones, las políticas de SST. Se ha puesto especial atención en los documentos relativos a la SST, y más específicamente, en dos documentos producidos por el MELS: el Informe de análisis de situación de la profesión, y el Programa de estudios. El primero fue realizado con la colaboración de expertos en la materia y constituye una base para la elaboración del segundo. Hemos inventariado y categorizado todos los enunciados vinculados con la SST. En este artículo presentamos un análisis comparativo entre los programas PEL y ESA. Se han identificado las competencias relacionadas con SST, los enunciados y los enfoques correspondientes, y de esta manera se han constituido las categorías: los aspectos que remiten a la aplicación de reglas de protección y los aspectos que remiten a comportamientos preventivos y reflexivos. en las trayectorias escolares y profesionales, su actividad en el CFP, los actores más importantes en cuanto a la SST, los desafíos, los factores que influencian las experiencias, las representaciones relacionadas con la SST, los accidentes y las lesiones profesionales, los proyectos profesionales y las necesidades con respecto a aspectos de SST. Con cada grupo de participantes, hemos abordado las cuatro dimensiones antes presentadas, pero haciendo énfasis en determinados aspectos según el rol de cada uno. Con los alumnos, todos mayores, hemos puesto el acento en su propia SST y en los contextos de aprendizaje. Les hemos preguntado qué es para ellos la SST, qué conocimientos rescatan sobre SST después de un año de formación, qué es lo que más los sorprendió de las visitas a los medios de trabajos, a qué tarea o manipulación le temen más. Los alumnos han completado, en sesión continua, un breve cuestionario auto administrado, en el que brindaban datos sobre su recorrido escolar y profesional, su situación familiar, sus actividades extra escolares y, dado el caso, sus dificultades de aprendizaje. las políticas y las prácticas en torno a la SST en el CFP, incluyendo los roles y las dinámicas entre sus actores.

Los esquemas de entrevistas y cuestionarios fueron diseñados a partir de tres contribuciones: la literatura, un esquema de entrevista desarrollado en colaboración con colegas ergónomos (Delgoulet, Santos y Veyrac) [5] y un proceso de validación con docentes voluntarios de otras escuelas. Las herramientas de recolección fueron validadas de acuerdo con las modalidades de pre test y pos test: los esquemas y cuestionarios utilizados con los docentes fueron convalidados con tres capacitadores de

Laboreal, Volume $10 \mathrm{~N}^{\circ} 2$ | 2014 
otro CFP, y luego modificados y testeados nuevamente con un capacitador del CF participante; aquellos relativos a los alumnos fueron evaluados por dos capacitadores participantes. Para el análisis de los datos de entrevistas, se constituyeron progresivamente unas categorías, con la ayuda de temas previamente definidos, así como de otros que surgieron de los datos recogidos (Paillé \& Mucchielli, 2003). En un comienzo, transcribimos las palabras textuales y los otros datos en función de los temas existentes, y luego desarrollamos la grilla de análisis de manera iterativa con la codificación de los datos. La interpretación de los resultados fue efectuada cruzando los resultados de los diversos métodos utilizados.

En los tres programas designados, las observaciones se han centrado en la actividad de los docentes y de los alumnos, así como en la actividad de los encargados de materiales en sus interacciones con los alumnos (sobre un total de 24 horas). Se prestó particular atención a los aspectos de SST (contextos, medioambientes, aspectos enseñados, experimentados, incidentes, accidentes).

Al finalizar el proyecto se dio lugar a la validación de los resultados, con la ayuda de entrevistas colectivas a 12 docentes participantes, 7 no participantes del CFP y 18 docentes de otros CFP, así como a dos grupos de directores de comisiones escolares y de CFP. La última etapa fue la de elaboración de las pautas de trabajo con los actores participantes y la de difusión de los resultados. Volveremos a ellas en la Discusión.

Cuadro 1. Síntesis de los métodos por categoría de participantes $(\mathrm{N}=75)$

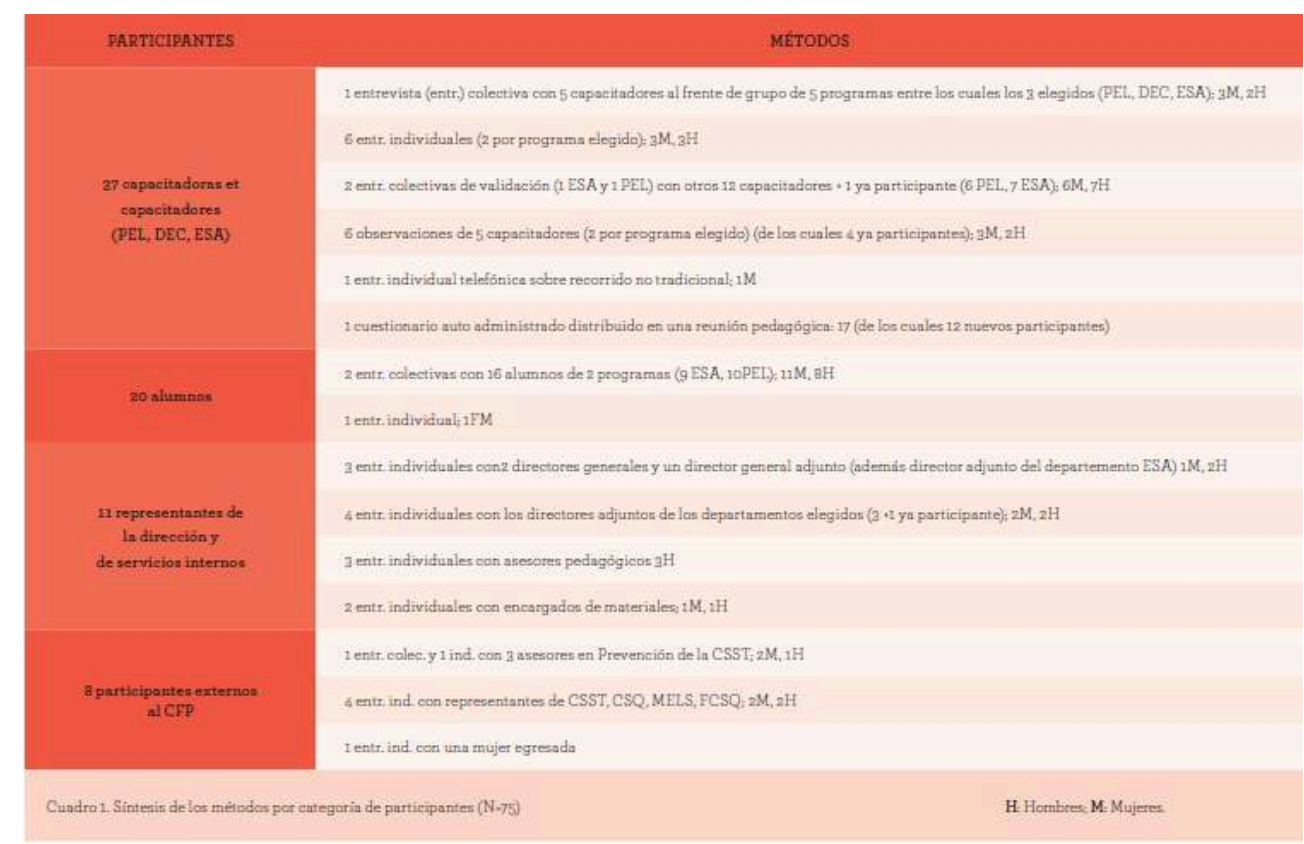

H: Hombres; M: Mujeres.

Los resultados presentados más arriba conciernen a los alumnos pero provienen de entrevistas y observaciones con alumnos y con otros grupos de participantes. 


\section{LAS CARACTERÍSTICAS DEL CENTRO DE FORMACIÓN, SU POBLACIÓN Y LOS ALUMNOS PARTICIPANTES}

El CFP está situado en una zona semiurbana, emplea a 146 docentes $(58 \mathrm{M}, 88 \mathrm{H})$ y recibe hasta 1500 alumnos. Ofrece más de 20 programas de estudio a tiempo completo. Las alumnas que cursan Peluquería son mucho más jóvenes que los alumnos que siguen Electromecánica de sistemas automáticos (ver cuadro 2). Han participado veinte alumnos: diez mujeres de Peluquería, ocho hombres y una mujer de Electromecánica de sistemas automáticos y una alumna proveniente de otro programa tradicionalmente masculino.

Cuadro 2. Sexo y edad de los 19 alumnos (sobre 20) de Peluquería y Electromecánica de sistemas automatizados y proporción hombres/mujeres en estos programas en Quebec.

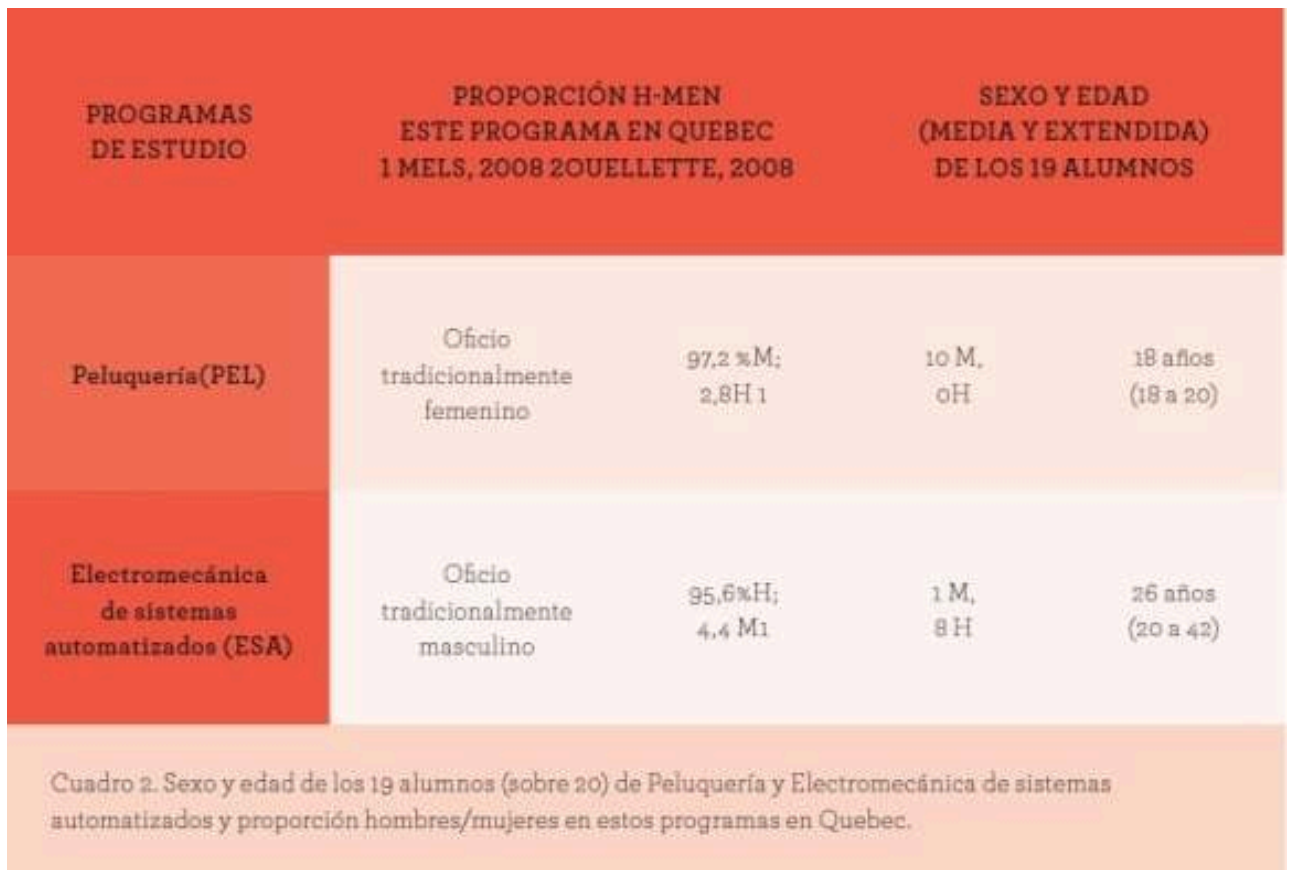

\section{RESULTADOS}

Presentaremos primero la diversidad de representaciones de la SST de los alumnos según los grupos de actores entrevistados, luego las condiciones de aprendizaje y sus efectos en la salud de los alumnos, y por último el enfoque de la SST en los documentos programáticos de enseñanza.

\subsection{La representación de la SST de los alumnos para los actores clave en el centro de formación}

Informaremos aquí acerca de las entrevistas con los representantes de la dirección, los docentes, los asesores, los encargados de materiales y por último los alumnos. Presentaremos algunos fragmentos representativos de los puntos de vista referidos $\mathrm{y}$, 
de ser necesario, de los puntos de vista divergentes. Llegado el caso, nos referiremos a las observaciones para apoyar o moderar los resultados de las entrevistas.

$$
\text { "estrictas" reglas de SST: vestimenta, uso de equipos de protección individual (por }
$$
ejemplo, gafas y botas de seguridad en ESA, calzado cerrado) y mantenimiento del puesto de trabajo en PEL. Dos puntos de vista se destacan en cuanto a la actitud de los más jóvenes. Algunos docentes refieren su falta de madurez debido a la edad y a la educación, como lo ejemplifica el siguiente extracto: "Son conscientes e inconscientes a la vez. Están en la edad en que creen que son inmortales, y ellos lo saben. Hay mucho polvillo, ellos mismos lo dicen y protestan, pero no se ponen sus máscaras." Sin embargo, uno de los docentes en PEL considera que ser joven es una ventaja, ya que no tienen todavía "malos hábitos" en sus métodos. Los docentes de PEL y ESA también consideran que los accidentes pueden ser ocasionados por la fatiga (mencionada como un estado generalizado en los alumnos jóvenes de PEL), y el consumo de drogas y de bebidas energizantes. "No podemos prohibirles la entrada a todos" en los talleres. Los docentes intentan, entonces, llevar a los alumnos al taller en los momentos del día en que parecen estar en mejor forma, pero no existe un momento ideal para todos. No sorprende entonces que la aplicación de las reglas sea fuente de disenso, o hasta de conflicto, en ESA, donde algunos docentes dicen que el clima "se pone duro" entre ellos y los alumnos. La situación produce inquietud para el docente y los docentes de PEL quienes, por un lado, constatan que los alumnos llevan un estilo de vida que entra en conflicto con sus estudios y, por otro lado, notan deterioros en la salud de sus alumnos, vinculados con las condiciones de aprendizaje.

31 Según los asesores pedagógicos: representaciones contrastadas

Laboreal, Volume 10 №2 | 2014 

el desarrollo de los contenidos y métodos de enseñanza y evaluación, particularmente en lo que hace a la SST. No juegan un papel directo con los alumnos, pero conocen parcialmente la realidad de los talleres de aprendizaje. Sus enfoques sobre la SST difieren, algunos consideran que los alumnos son inconscientes y temerarios y que hay que impactarlos para que comprendan la importancia de prestar atención: "Cuando era docente, intentaba traumatizarlos con imágenes fuertes para hacerlos reaccionar". Ahora bien, paradójicamente, este asesor prefiere actualmente mantener distancia con los talleres a causa de los riesgos implícitos en el entorno: "Hay que prestar atención a dónde uno apoya el pie, [...] wow. Ellos están habituados, no sé cómo hacen, pero yo no, ya he tenido dolores de cabeza, es por eso que pongo un límite a mis desplazamientos, le digo al profesor que venga a verme." Este asesor refiere entonces condiciones de enseñanza y aprendizaje a riesgo. Alude también a competencias de prudencia que los docentes y los alumnos han desarrollado. Pero estos aspectos no están integrados en una reflexión pedagógica y en el discurso sobre la relación de los alumnos con la SST. Por el contrario, otro asesor busca desempeñar un papel cerca de los docentes para favorecer la integración de la SST desde la redacción del plan del curso, en cada etapa, para concientizar a los alumnos sin "infundirles miedo". Estos dos asesores están afectados a programas tradicionalmente masculinos, donde se encuentran máquinas y equipos que pueden producir heridas graves. El tercer asesor, afectado a programas tradicionalmente femeninos que implican menos equipos pesados, no conoce los riesgos en el taller y declara que no busca intervenir sobre temas de SST. materiales: inventario, selección y pedido de equipamientos, materiales y productos: como por ejemplo, electrodos, pulidoras y gas en ESA; maniquíes, tijeras y colorantes en peluquería; diversos equipos de protección individual de acuerdo con los programas y las tallas de los alumnos (por ejemplo, guantes, abrigo, casco, gafas, calzado de seguridad). Conocen a los alumnos, dado que estos pasan por sus comercios varias veces por día para retirar equipamiento, herramientas, y a menudo para recibir las primeras curaciones. Los encargados de materiales disponen, en efecto, de un botiquín de primeros auxilios del departamento y lo proveen "todos los días". Durante una observación de una hora en la tienda, se presentaron cuatro alumnos para recibir curaciones por cortes en las manos con tijeras. Los encargados de materiales aprovechan estas interacciones con los alumnos para hablar con ellos. Los consejos más frecuentes conciernen a la elección de los equipos. Por ejemplo, los alumnos de ESA tienden a evitar el uso de algunas herramientas que sienten demasiado pesadas, pero que son necesarias para determinadas tareas. Es una oportunidad para proponerles estrategias de utilización de herramientas peligrosas y comentarles la importancia de buscar primeros auxilios aunque la herida parezca menor. Los encargados de materiales dicen que hablan poco de SST con otros actores. controlar las posturas

Estas alumnas definen la SST, en primer lugar, por la protección de la clientela: "primero la cliente, después una misma", "por ejemplo, colocar bien la capa y la crema de coloración". Ellas creen que la salud y seguridad en el trabajo concierne a la clientela. Encontramos entonces un deslizamiento de sentido que, según veremos, 
proviene del Programa de estudios. Por supuesto, puede existir una relación entre la SST de la trabajadora y la comodidad de la clientela. Pero, los únicos ejemplos que ellas encuentran son los impactos de su trabajo sobre la clientela. Ellas mencionan, por otra parte, la protección del entorno de trabajo para prevenir las caídas de las clientas y del personal: barrer los cabellos, acomodar los útiles, las toallas e hilos, y secar el agua del suelo. En su definición de la SST, las alumnas mencionan la presencia de sustancias químicas en el aire. Ninguna habla de la dureza de las limitaciones posturales, a las que sí aluden ampliamente, sin embargo, en sus respuestas a las preguntas posteriores.

Lo que ellas resaltan de su formación es "la importancia que los docentes les dan a las buenas posturas, en todos los módulos de la formación", de su entrenamiento y evaluación: "los docentes se refieren a eso todo el tiempo, prestar atención para proteger la espalda y los hombros, estirarse"; "sentarse", "masajearse". Las alumnas reconocen la importancia de controlar la postura, pero son escépticas en cuanto a los efectos de las medidas (individuales) recomendadas, pues ya sienten dolores repetidos y constatan que sus docentes, aún si han dejado de practicar el oficio, los padecen también. Los dolores las inquietan porque sienten que no pueden evitarlos a pesar de que intentan controlar la postura. Una de ellas expresó bien esta preocupación: "Es por el cuerpo, recién comienzo, estoy todavía en mi formación y ya me duele el brazo, y sobre todo las piernas. Y eso que todavía no trabajo, estoy todavía estudiando". En algunas de ellas, este temor está acompañado por una especie de resignación. "Cuando ya tienes el cuerpo arruinado, hacer estiramientos no sirve de mucho". "A medida que trabajas, tu cuerpo se debilita. Las ves (a las peluqueras) estar así, de pie, 5 o 6 horas sin parar, mejor me acostumbro a eso porque el trabajo de oficina no es para mí". Las actividades observadas en el local-escuela revelaron un trabajo de pie prolongado con pausa optativa para las alumnas. Es el modelo que observan en la docente, que durante las observaciones no se sentó nunca ni hizo pausas. Por otra parte, las alumnas retienen la importancia del mantenimiento sistemático del puesto de trabajo, aunque cuestionan que esto sea posible en la realidad con relación al tiempo de que se dispone en el salón de peluquería (por ejemplo, desinfectar "todo el tiempo" los cepillos y el pie de la silla después de cada cliente), y la presencia de riesgos asociados a los productos químicos, pero no recuerdan ningún medio de prevención. Las observaciones han permitido efectivamente constatar los esfuerzos y los obstáculos para adoptar posturas confortables y para mantener sistemáticamente los lugares de trabajo, debido a deficiencias en el equipamiento (sillas y lavabos poco o nada ajustables), espacios estrechos y obstruidos, y limitaciones temporales.

Ante la pregunta "¿Hay alguna tarea o manipulación a la que le temas más con relación a tu salud?", las alumnas hablan de diversos aspectos: las frecuentes heridas durante los cortes de cabello debidas a la falta de experiencia (lo que confirma una hipótesis expresada por las autoridades); los cortes producidos en el momento de acomodar objetos cortantes (tijeras, navaja); las quemaduras con el rizador; las manipulaciones de productos químicos (hemos observado que no utilizan guantes, que trabajan inclinadas sobre los productos y que la ventilación es escasa); el temor a contraer enfermedades de la piel por contacto con la clientela.

39 Ante la pregunta “¿Qué saben de la SST en la escuela?” la mayoría de las alumnas menciona como un factor de estrés el cruzarse con algunos alumnos hombres: "Las chicas, cuando vamos a la cafetería y los muchachos están ahí, sobre todo los de la construcción"; "es bestial"; "somos un pedazo de carne". Ellas ya lo han hablado con 
sus capacitadores, quienes han minimizado la importancia de estos hechos, cosa que las lastima. Las alumnas no mencionan los factores de estrés asociados a los clientes que vienen a hacerse atender en la peluquería-escuela, ni a las condiciones de trabajo como la ausencia de pausas o los horarios prolongados, identificados en el informe de análisis de la situación de trabajo (AST) presentado más adelante. No obstante, cuando se les pregunta qué les ha impactado al visitar lugares de trabajo, ellas responden que es la dureza de las posturas, y también el ambiente de trabajo "no necesariamente bueno", sino por ejemplo frío y competitivo. A pesar de esto, ellas estiman que las condiciones que encontrarán en las peluquerías serán mejores que las del salón-escuela. Por otra parte, dos alumnas refirieron haber sido desalentadas por sus seres próximos al haber elegido peluquería por la utilización de productos nocivos para la salud y por la desvalorización social del oficio.

Según los alumnos de Electromecánica de sistemas automáticos (ESA): la responsabilidad es compartida, pero sobre todo se deben respetar las reglas.

41 En ESA ( $n=9)$, los alumnos aportan una distinción que en las alumnas de PEL no aparece. Definen a la SST en función de la división de las responsabilidades: las del empleador (organización, formación, equipos) y las del trabajador (competencias, actitudes). Mencionan diversos factores que influyen en la SST: la presión que sufren los empleadores y los clientes afecta a las condiciones, las decisiones y la salud: "a menudo el accidente se produce cuando quieres apurarte"; "la compañía pierde dinero cuando la máquina se detiene, y también se calcula el tiempo de detención"; "quieres apurarte y pasas por alto las medidas de protección"; la gestión de la productividad "cuanto más se quiere producir, más cae la SST"; los horarios prolongados ("[...] el sábado y el domingo, condiciones de trabajo agotadoras"), y los problemas de acceso a las herramientas. Lo que ha impactado a los alumnos en sus visitas a lugares de trabajo son los horarios de trabajo prolongado para asegurar la funcionalidad de los sistemas complejos: "no se termina hasta que el sistema no está funcionando, la responsabilidad es grande". Por otra parte, ellos identifican las medidas organizacionales e individuales para minimizar los riesgos pero ninguna de ellas apunta a la prevención desde el origen: estar formado e informado sobre los peligros de las máquinas, saber trabajar con los equipos y técnicas adecuados, ser humilde, "no tener demasiada confianza en nuestros medios".

De esta manera, se puede observar que han desarrollado una cierta comprensión de la dinámica de los medios de trabajo. Pero, algunos de ellos se inquietan por la falta de consideración de sus docentes de las diferencias entre la escuela y la empresa: "tenemos el mejor sistema de ventilación [en la escuela] pero cuando pasas a una pequeña empresa, la ventilación es la puerta del garaje abierta y seguro que todo el tiempo hay humo que uno respira"; "nos hacen creer que es una práctica corriente [uso de gafas, bloqueo [6] aún si no lo es en la realidad". "No nos dicen [...] que a nuestros jefes los tendrá sin cuidado". "Las compañías no consideran eso, su mentalidad no es compatible con la SST". "Haces lo que puedes". Sin embargo, no todos se resignan "hay que imponerlo", dice un alumno, dando pruebas de un posible poder (las muchachas en PEL nunca sugirieron la posibilidad de influir en las condiciones de trabajo).

Como las alumnas de PEL, lo que los alumnos de ESA rescatan de su formación es la sensibilización en el respeto a las reglas. Para ellos, esto no solamente se traduce en recordatorios de las reglas (utilizar los equipos de protección, bloquear las máquinas), sino también en carteles en los talleres sobre el uso de gafas y botas, sobre los 
accidentes graves con máquinas idénticas a las utilizadas en la formación. El bloqueo es la manipulación que más temen; les da miedo cometer errores críticos para su seguridad y la de los otros. Los alumnos destacan que los capacitadores son atentos y responsables en el cuidado de sus alumnos y en enseñarles a protegerse, pero que el docente no puede vigilar a todos los alumnos al mismo tiempo. Los alumnos temen también los efectos nocivos del ruido en los talleres, a pesar de utilizar las protecciones auditivas.

Tres alumnos fueron desalentados por sus seres próximos al elegir ese oficio, de los cuales uno a causa de los aspectos físicos de SST: "vas a perder un dedo antes de los 30 años". Las otras opiniones negativas recibidas estaban relacionadas con el riesgo para la salud psicológica de ser una mujer en este oficio tradicionalmente masculino y estar expuesta a comportamientos sexistas; y con la poca valorización del oficio en comparación con otros como el de mecánico industrial.

\subsection{Las condiciones de aprendizaje y sus efectos sobre la salud}

El análisis del registro de accidentes, las observaciones y los cuestionarios auto administrados permitieron una comparación más sistemática de las condiciones de aprendizaje y de los impactos percibidos por los alumnos de PEL y de ESA. Los resultados confirman que hay diferencias entre los contextos, y permiten identificar causas asociadas con las particularidades de los oficios y con una atención diferente de la SST por parte de la organización. Presentaremos aquí en primer lugar la situación en PEL, luego en ESA, y por último la de las mujeres en programas de estudio tradicionalmente masculinos.

La situación en los talleres de Peluquería (PEL)

El departamento de PEL está integrado por clases convencionales rodeadas de pequeños elementos para practicar las operaciones sobre maniquíes o sobre otras alumnas. Tiene también un local más grande provisto de mobiliario y equipamiento parecidos a los de un salón de peluquería (mesitas auxiliares, sillas de peinado, lavabos, secadores, rizadores, etc.). Se trata, de todas formas, de un espacio insuficiente para la cantidad de personas, con espacios de circulación estrechos y obstruidos. Los equipos pequeños y materiales deben ser extraídos de la sala de materiales de acuerdo a las necesidades específicas de cada aprendizaje (tijeras, productos capilares, etc.). La mitad de los locales ha sido renovada. Los capacitadores califican a los otros locales como insalubres (filtraciones de agua, humedad, moho) y disfuncionales (falta de espacio, puestos de trabajo y equipamiento insuficientes, en mal estado y poco adecuados para el talle de los alumnos). Hemos observado estos problemas, así como un ruido intenso y un fuerte olor de los productos de coloración. Las docentes dicen estar cansadas de pelear por pocos resultados. En una entrevista colectiva en la que ellas participaron junto a docentes de otros programas, pudieron constatar diferencias en la atención de la dirección a sus pedidos, y más específicamente en la rapidez con que atienden los pedidos provenientes de los departamentos "masculinos". También hemos visto que los alumnos corroboran la apreciación de que algunas de sus condiciones de aprendizaje son problemáticas.

En el registro de accidentes provisto por la escuela (2008-09) no se había consignado ninguna herida, ni los alumnos habían informado de ninguna herida que hubiera causado una ausencia desde el comienzo de su capacitación. No hay inventario 
disponible de los incidentes y dolores que den cuenta del deterioro de las instalaciones ni de la salud. Sin embargo, nuestras entrevistas revelan que cotidianamente se producen heridas llamadas menores. Seis alumnos $(\mathrm{N}=10)$ han sufrido heridas (cuadro 3) pero ninguna fue declarada ante la dirección de la escuela. Dolores músculo esqueléticos recurrentes o permanentes aparecen en la mayoría de los alumnos, quienes afirman que estos dolores están ligados con las clases en los talleres (contrariamente a otros, que están asociados a situaciones extra escolares). El trabajo de pie y las posturas limitantes predominan entre las causas. Tres alumnos identifican también a los movimientos repetitivos en la utilización de tijeras y al transporte de toallas limpias y sucias. Todas las capacitadoras confirman estos dolores y señalan al mobiliario y al equipamiento como los causantes: "Todas las alumnas tienen dolor de espalda", dice una de ellas. Por otro lado, nuestras observaciones muestran que la duración de las clases exige permanecer por tiempo prolongado en posturas problemáticas.

Cuadro 3. Heridas y dolores identificados por los alumnos de Peluquería (PEL) y de Electromecánica de sistemas automáticos (ESA), en relación con sus actividades de aprendizaje en el centro de formación.

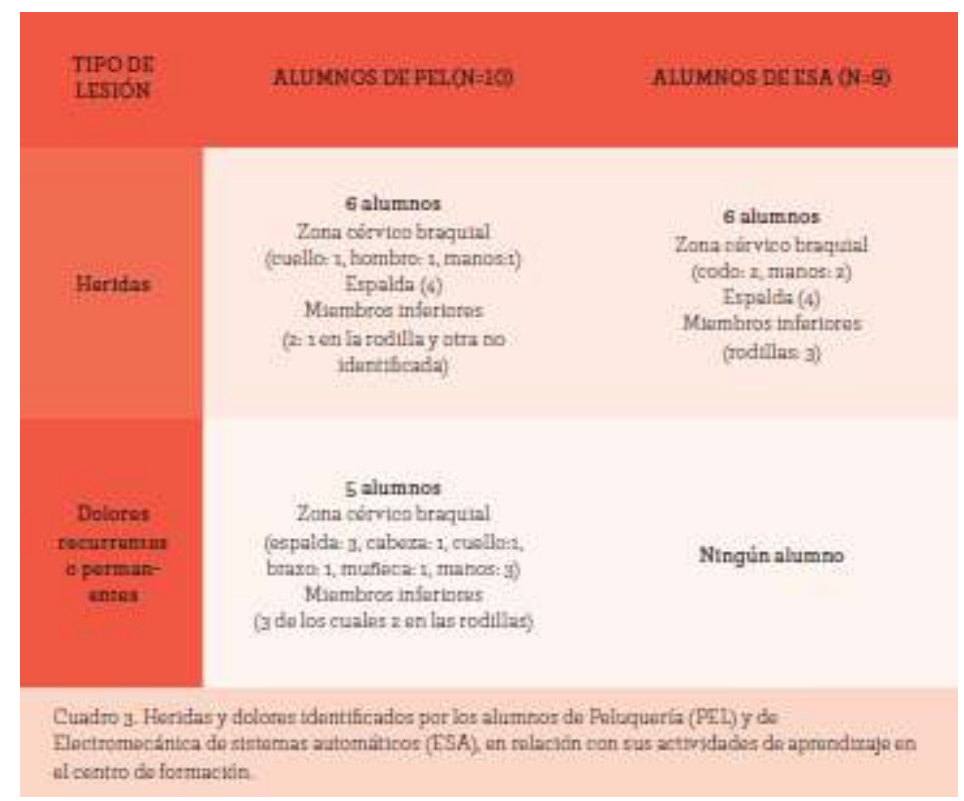

Ante el hecho de que las docentes se quejan por el estado de cansancio de las alumnas, que atribuyen a su modo de vida, hemos interrogado a las alumnas acerca de la cantidad de horas trabajadas y el tipo de trabajo efectuado. Todas las alumnas trabajan en forma paralela a sus estudios, un mínimo de 15 horas semanales hasta 46 horas. Ellas son cajeras (4), mesera, vendedora y asistente en un salón de peluquería. Es posible entonces que estos empleos estén involucrados en la aparición y/o permanencia de dolores de espalda y de miembros inferiores. En cuanto a la afección de los miembros superiores, son sobre todo la mesera y la asistente de peluquería quienes pueden estar doblemente expuestas, pero habría que analizar la actividad para comprender el trabajo de cada alumna-trabajadora y su relación con el estado de salud, en particular el tipo de postura de pie, con o sin desplazamientos, que influye de manera diferente en la salud (Messing \& Chatigny, 2004). Nuestros resultados nos permiten, no obstante, afirmar que las condiciones de aprendizaje en el centro de formación, identificadas y confirmadas gracias a la triangulación de las fuentes de datos, tienen riesgos con 
respecto al desarrollo de dolores y trastornos músculo esqueléticos. Aunque el presente artículo no se refiere a la SST de las docentes, es importante mencionar que el patrón de dolores músculo esqueléticos de las alumnas corresponde casi en su totalidad con el de sus capacitadoras (Chatigny et al., 2011). En efecto, estas padecen dolores en las mismas zonas corporales con relación a la práctica (anterior o actual) de su oficio y a las condiciones de trabajo en el centro de formación, que las exponen parcialmente a los mismos riesgos. convencionales, llamados de "teoría"; aulas rodeadas de pequeños equipamientos para "dar teoría" y hacerles practicar algunas operaciones (por ejemplo, tableros de control o de montaje); y un inmenso taller-sala de máquinas similar a las de las grandes empresas. Las observaciones mostraron un espacio claro, aireado, limpio, poco ocupado, con zonas de circulación y de trabajo indicadas en el piso. Se han realizado inversiones importantes para reducir los riesgos de seguridad (electricidad, polvos, caídas, cortes) por pedido de la Comisión de salud y seguridad en el trabajo (CSST). Los capacitadores y los alumnos consideran que su entorno es superior al que se encuentra normalmente en el mercado de trabajo. Ellos informan, sin embargo, que en el conjunto de los locales hay problemas de arquitectura, de espacio y de distribución que producen un aumento de los desplazamientos y los privan de un buen contacto capacitadoralumno, lo que representa una gran fuente de estrés, sobre todo para los docentes. Nuestras observaciones confirman las limitaciones espaciales en algunas zonas de trabajo, que ocasionan especialmente maniobras de riesgo (por ejemplo, tener que trepar por sobre los equipos para alcanzar una alacena, golpearse o tropezar con otro alumno al mover un objeto).

Cuadro 4. Accidentes con heridas, identificados en el registro de accidentes del período 2008-2009

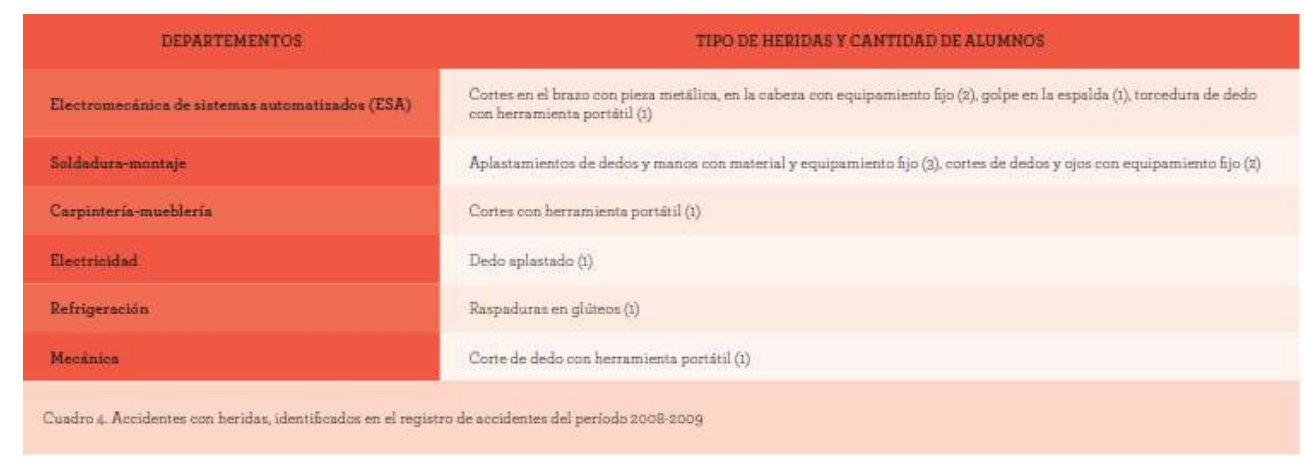

Todos los accidentes inventariados en el registro del establecimiento (2008-09) se produjeron en departamentos tradicionalmente masculinos (cuadro 4). En lo que concierne a ESA, se trataba de cortes, golpes y torceduras. La dirección estima que se ha hecho cargo de estas situaciones. Sin embargo, como lo vimos anteriormente, no hubo investigación de los accidentes. En los alumnos participantes ( $N=9$ ), las encuestas revelan que seis de ellos han sufrido heridas que a menudo afectan más de una zona corporal. La espalda y las rodillas son las más afectadas. Los alumnos atribuyen sus heridas a problemas posturales y malos movimientos. Es sabido que el establecimiento no se hace cargo de estos factores, pues por el momento se concentra en los riesgos asociados a la operación de máquinas. 

y máquinas. Esta situación los preocupa, aún si los riesgos han disminuido después de las intervenciones de la CSST. La ausencia de un análisis de los accidentes e incidentes en este centro de formación no permite llegar muy lejos en la comprensión de las causas, pero una cosa es cierta: las condiciones objetivas, identificadas gracias a la triangulación de las fuentes de datos, permite confirmar que, a pesar de las mejoras realizadas en el transcurso de los dos últimos años, existen riesgos múltiples de corte y aplastamiento asociados al tipo de máquinas, a la falta de espacio en ciertas zonas de trabajo, a la falta de experiencia y a los métodos de trabajo. remunerado a tiempo completo. Trabajan, según el caso, desde 4 horas semanales a 43 (media de 28,5 horas por semana), como asistente (2), instalador de puertas y ventanas, mecánico industrial, panadería o técnico operador. Uno de ellos acumula dos empleos, de camionero y de asistente electromecánico. Estos empleos implican exigencias físicas, pero los datos no permiten establecer una relación entre estos y las heridas ocurridas en la escuela. Contrariamente a las alumnas de PEL, ninguno de ellos informa sobre dolores recurrentes o permanentes. Esto hace pensar que la salud músculo esquelética no se ve afectada por estos empleos paralelos, aunque esto sería verdaderamente sorprendente, considerando el trabajo de pie prolongado durante el aprendizaje en la escuela. Una muestra más grande de participantes permitiría verificarlo. En lo que concierne a la salud psicológica, la situación de las alumnas en los programas predominantemente masculinos es preocupante. Trataremos este problema a continuación, ya que toca a mujeres en varios programas de estudio en el centro de formación participante, así como en otros establecimientos.

Las participantes provenientes de programas de estudio mayoritariamente masculinos ponen en evidencia otros riesgos, que son consecuencia de enfrentar como minoría femenina culturas de oficios que valorizan la demostración de fuerzas viriles por sobre la prevención de riesgos de SST y que tienden a rechazar la presencia femenina. Hemos entrevistado a tres mujeres; dos son alumnas y una había finalizado recientemente su capacitación. Los resultados han sido validados con alumnas de otros programas de estudio. Estas mujeres no tropiezan necesariamente con todas las dificultades que siguen, pero todas ellas han vivido ciertos de estos obstáculos, y pueden corroborar su existencia en sus medios de capacitación o de trabajo. Ahora bien, la salud psicológica, como ya lo hemos visto, raramente es considerada en el medio escolar como una dimensión de la SST.

Las participantes refieren que, en general, son bien aceptadas en el entorno escolar. Expresan que los capacitadores (todos masculinos, lo que no siempre es el caso en todos los programas predominantemente masculinos) intervienen generalmente si observan comportamientos inadecuados en los alumnos. Las intervenciones más eficaces son las de los capacitadores que intervienen firmemente, por ejemplo, advirtiendo al alumno que se comporta inapropiadamente que puede dejar la escuela si no le interesa. Los capacitadores intentan entonces controlar este tipo de situaciones pero estas se producen y a veces se prolongan en el tiempo. Ese fue el caso de una alumna (aquí debajo M) en un grupo de alumnos (H). Cuatro de ellos cuentan orgullosos la situación siguiente a la investigadora (I) en un intercambio sobre los riesgos físicos: 
H1: Y sí, nosotros la desalentamos pero ella sigue acá.

I: ¿Qué le dijeron?

H2: No se puede decir aquí (risas).

H3: Todos los chistes sexistas [..]

H4: En realidad la preparamos para su futuro trabajo.

I: ¿Y funciona?

H4: Ella sigue acá, ha funcionado.

H3: Es la prueba de que ella quiere hacerlo.

M: Es un buen anticipo de lo que será. Dicen que no va a ser fácil al principio...

58 La alumna escucha este relato y expresa dos cosas a sus compañeros: que ella comprende que volverá a vivir este tipo de situación cuando se inserte en el mercado de trabajo, y que esto tiene un impacto negativo en su estado de salud. Después de algunos minutos, un quinto alumno intenta diferenciarse de las palabras de sus compañeros reafirmando la capacidad de una mujer que lo había formado anteriormente, y que las mujeres tienen un lugar en ese oficio; los otros alumnos, en cambio, no expresan nada. Investigaciones anteriores han demostrado que es suficiente con que haya un compañero con actitud negativa para que la situación se transforme en problemática hacia las mujeres en contextos no tradicionales, y que si un colega masculino defiende a su compañera, corre el riesgo de ser excluido del grupo él mismo (Couture et al., 2004). En este caso, la frecuencia y la amplitud de las "bromas" evocadas en el relato, la falta de conocimiento sobre el acoso, así como la gran cantidad de comportamientos de diversos tipos que los capacitadores deben controlar en el transcurso de una jornada, permiten pensar que el capacitador pudo haber estado al corriente pero no intervino (aunque no lo hemos verificado). Por otra parte, los capacitadores confirman que hay situaciones que ellos "dejan pasar": en cuanto a las reglas de SST, por falta de tiempo y por evitar molestar a los alumnos; en cuanto a las alumnas mujeres, algunos confiesan no saber cómo comportarse ante las situaciones de acoso.

El conjunto de entrevistas con las alumnas en contexto no tradicional pone a la luz que ellas pueden tener problemas en el colegio pero que en las pasantías el medio es peor. Un primer obstáculo es el de obtener un lugar para la pasantía y luego, una vez conseguido, tener acceso a un acompañamiento apropiado y tareas pertinentes a los contenidos pedagógicos, así como integrarse al grupo. La mayoría de las mujeres han vivido situaciones discriminatorias: cuestionamientos sobre la pertinencia de su presencia en esos empleos; denigración de sus competencias y capacidades físicas; aislamiento, agresiones verbales (y físicas, en un caso), palabras degradantes de carácter sexual y requerimientos sexuales. El siguiente extracto ilustra el impacto psicológico y físico que estas situaciones pueden implicar.

\footnotetext{
“No caí en una buena empresa. Ellos sabían que me tenía que quedar allí para obtener mi diploma. No me daban gran cosa para hacer, barría solamente [...] La primera semana me hicieron hacer todo lo posible para que me fuera. Después de un mes, uno de ellos me apoyó en un rincón. Me fui. Hablé con mis profesores y ellos me dieron el diploma igual. Después de eso, me he sentido siempre estresada en todas las empresas a las que fui. Me sentía mareada y perdí el conocimiento no sé cuántas veces".
}

Saber darse su lugar, responder a las bromas o ignorar los comportamientos provocadores sólo son algunas de las estrategias de regulación de los comportamientos sexistas. Sin embargo, una investigación anterior demostró que estas estrategias no 
siempre son eficaces en el tiempo, ni con todos los hombre (Couture et al., 2004). Algunas mujeres que creían haber ganado su lugar han terminado por dejar el empleo $\mathrm{y}$, en ciertos casos, han vuelto a empleos tradicionalmente femeninos por los que no tenían interés. Las participantes refieren que los comportamientos discriminatorios provienen menos de hombres jóvenes que de sus mayores, incluidos los representantes sindicales. Sin embargo, los alumnos que hablaron de las presiones ejercidas sobre la alumna (más arriba) formaban parte del miso grupo etario que ella. Por el contrario, determinadas situaciones son favorables para la inserción: recibimiento y apoyo por parte de sus colegas y de la dirección, colegas de la misma edad, presencia de otras mujeres, reconocimiento de sus competencias.

Por otro lado, las participantes se sorprenden por la relación con la seguridad que a menudo es diferente en los hombres. Ellas observan que se preocupan más por la seguridad que sus colegas masculinos. "[...] Se diría que los hombres hacen algo como: «Miren, puedo hacerlo y lo hago bien», y se sube al techo sin atarse. Es suficiente que patine accidentalmente para correr el riesgo de caerse y morir [...]"; cree que se verá afeminado si se pone un arnés".

Veremos a continuación, en esta última parte de los resultados, que las representaciones de la SST y las situaciones de aprendizaje están también relacionadas con las prescripciones ministeriales para la enseñanza de oficios sobre las cuales se basan los analices siguientes.

\subsection{Enfoque de la SST en los materiales programáticos de la enseñanza}

63 El Informe sobre análisis de la situación de trabajo (AST), realizado para orientar el desarrollo del Programa de estudios, se apoya en un análisis colectivo realizado con representantes de los medios de trabajo (y con frecuencia de capacitación) y un observador de la CSST, quien luego elaboró una lista documentada de los riesgos SST. Si bien el AST no contiene un análisis de la actividad de trabajo, provee en cambio informaciones útiles sobre el oficio y sobre los riesgos específicos: una descripción general del oficio y de los contextos de práctica, tareas y operaciones, conocimientos, habilidades y aptitudes requeridas, y sugerencias para la enseñanza. Sin embargo, este documento no se encuentra disponible para los capacitadores ni los alumnos. El documento de referencia impuesto para la enseñanza y el que dicta las competencias que deben adquirirse es el Programa de estudios. Así, cada competencia corresponde a un módulo de formación de una duración determinada. Los AST y Programas de estudio de peluquería (PEL)y de electromecánica de sistemas automatizados (ESA) no han sido revisados recientemente (Ministère de l'Éducation, 1999, 2000, 2001, 2004). No obstante, el estudio de estos documentos permite una cierta comprensión de los oficios referidos y de los aprendizajes esperados. Más específicamente, en lo que concierne a la SST, el análisis ha permitido identificar las similitudes y particularidades, y comparar los enfoques y el tratamiento de la SST en la enseñanza de ambos oficios. Los aspectos de la SST varían entre PEL y ESA dado que las tareas, exigencias y riesgos asociados a estos oficios difieren. Sin embargo, como veremos, estos factores no pueden explicar por sí mismos las diferencias en el tratamiento de la SST en los dos oficios.

La SST en el Informe sobre el Análisis de la situación de trabajo (AST) 

de trabajo estresantes (PEL: clientela; ESA: detenciones de la producción, presión de los superiores, horas de trabajo prolongadas, decisiones difíciles, y/o empresas poco interesadas en la SST). Ahora, en PEL, estos aspectos no figuran en la sección SST sino en la de las habilidades psicológicas a desarrollar. La sección los riesgos en la SST aborda solamente la presencia de riesgos químicos y posturales. Los otros riesgos físicos, como los esfuerzos estáticos prolongados, no aparecen, igual que los riesgos psicosociales y biológicos. Los riesgos químicos y posturales son abordados en términos de respeto a las reglas no enunciadas y solamente para algunas de las "competencias" que exige la utilización de productos químicos (4/17: alisar, colorear, decolorar, mechas). El anexo producido por la CSST amplía a otros tipos de riesgos (incendios, electricidad, ventilación, instalaciones, posturas, equipos, herramientas, productos químicos, métodos de trabajo). Se constata la ausencia de elementos de SST en varias "competencias" y una falta casi total de prevención en origen. Todo recae en la responsabilidad individual.

En el AST de ESA, la SST es abordada en casi todas las "competencias" identificadas (11/13) (Código eléctrico, Ley sobre salud y seguridad en el trabajo) por referencia a normas específicas de un sector de empleo (relativas al sector alimentario, por ejemplo) y a reglas a respetar en cuanto al manejo de productos peligrosos, trabajo en altura y en aislamiento, trabajo físico, equipamientos, espacios, ruido, olores, calor. Saber ser disciplinado y prudente permitiría hacer de los riesgos algo "manejable" (Ministère de l'Éducation, 2004, p. 5). Al igual que en PEL, los enunciados remiten sobre todo a controlar comportamientos. Sin embargo, aquí aparece actuar un aspecto nuevo que es la posibilidad de actuar sobre los riesgos, el cual, como veremos, es retomado en el programa de estudios. No obstante, en el AST aparece un mensaje contradictorio cuando se especifica que "[...] la responsabilidad de la seguridad en el trabajo compete siempre al trabajador" (p. 5), enunciado contrario a la ley (LSST, L.R.Q., S-2.1) que estipula une responsabilidad compartida entre el empleador y el trabajador.

Veamos ahora cómo estos análisis se traducen en los programas de estudio, con una cantidad más elevada de competencias. Este incremento se explica parcialmente por el añadido de competencias consideradas como no específicas del oficio. Es el caso, por ejemplo, del módulo (competencia) oficio y formación, que se encuentra en todos los programas de estudio.

La SST en el Programa de estudio

El programa de estudio de PEL es de 1455 horas para adquirir 21 competencias. El programa de ESA dura 1800 horas y cubre 27 competencias. Los dos programas incluyen un módulo de 30 horas consagrado a la SST, casi al inicio de la capacitación. Esta "competencia" en SST está considerada como "general", es decir, no específica al oficio, excepto en algunos programas que contienen una competencia SST reconocida como específica del oficio, dando pruebas de una mejor comprensión de las competencias en SST correspondientes a cada oficio y a cada contexto. La SST es abordada de un modo teórico con actividades pedagógicas de transmisión y descubrimiento de los conocimientos en materiales de referencia. Se evalúa sobre la base de una participación activa, no sobre el manejo de conocimientos y competencias. En el programa de PEL, el módulo SST se limita a objetivos de aplicación de reglas, mientras que el de ESA es un poco más rico, con objetivos de reflexión, análisis y eliminación de los riesgos que brindan un cierto poder de acción. A pesar de esto, los aspectos legislativos dominan en 
la enseñanza de ESA porque el documento de referencia realmente utilizado está vinculado con las normas de SST en el sector de la construcción y de la CSST. La enseñanza es ejercida por capacitadores o docentes acreditados por la Association sectorielle paritaire pour la SST secteur construction - Asociación sectorial paritaria para la SST del sector construcción-. Los docentes que hemos visto en el CFP refieren no disponer de margen de maniobra para adaptar y modernizar el contenido.

Otros módulos de capacitación incluyen aspectos de SST (por ejemplo, Tratamiento de los cabellos y del cuero cabelludo, o Mantenimiento de los dispositivos mecánicos). El programa provee entonces, para cada competencia, indicaciones que remiten sobre todo a las prescripciones que llamaremos "de aplicación de reglas de protección"(cuadro 5). En PEL, esto se traduce en reglas de higiene, de seguridad, de peinado (por ej., aplicación justa de medios de prevención de dermatosis, realización sujeta a pruebas cutáneas (sobre el cliente). Si bien puede existir una relación entre la seguridad de la peluquera y la del cliente, esta no se explicita. La seguridad del cliente es abordada como un aspecto de SST. Este deslizamiento se repite en otros módulos e introduce una confusión con respecto a la persona aludida en realidad por la SST, la trabajadora.

Cuadro 5. Enunciados relativos a la SST en los programas de estudio de Peluquería y de Electromecánica de los sistemas automatizados (en negritas, los aspectos que pueden procurar un cierto poder de acción sobre la prevención).

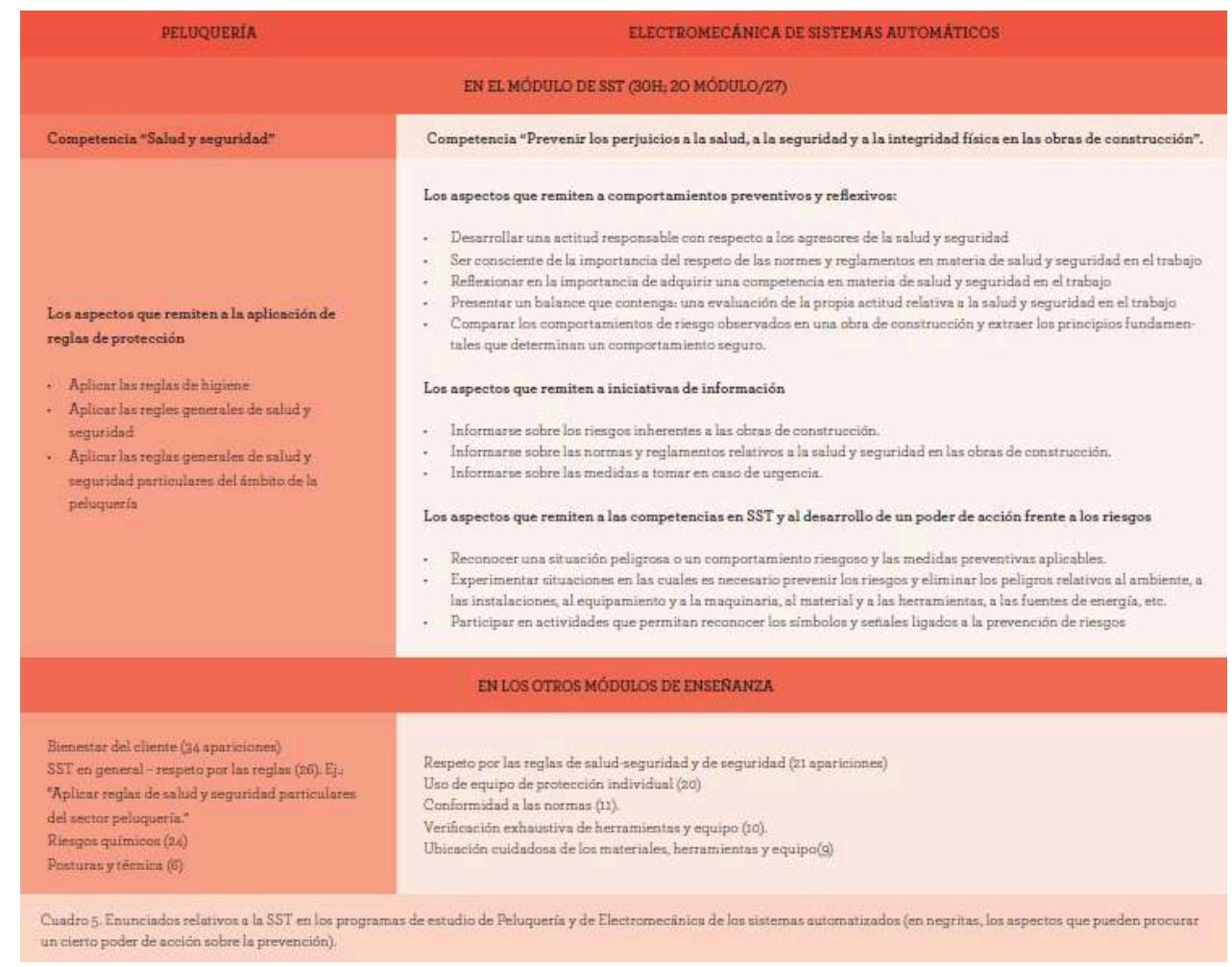

71 Se incita a los alumnos a "aplicar" las instrucciones de SST relativas a las reglas establecidas por el colegio y por los docentes. Los primeros descubren progresivamente diversos riesgos asociados a las tareas y a los entornos en los que se desenvuelven. Las entrevistas con los docentes muestran que ellos hablan a menudo sobre los métodos de trabajo para realizar las operaciones previstas. Por el contrario, explicitan poco sus propias estrategias de prudencia cuando realizan las demostraciones. Las entrevistas 
revelaron que la mayor parte de ellos nunca había tenido la oportunidad de compartir sus prácticas del oficio y de la enseñanza de SST. Estas competencias se incorporan firmemente y son difíciles de explicitar (Leplat, 1997). El saber hacer de prudencia, que constituye un componente importante del saber hacer eficiente (Ouellet \& Vézina, 2009), sólo son abordados parcialmente. Entonces, cuando se les pregunta cuáles son sus prácticas de enseñanza en SST, mencionan sobre todo las reglas de SST. Como denotan las observaciones, ellos mismos incorporan, sin darse cuenta, diversos aspectos de SST en su planificación y enseñanza. Sería, no obstante, necesario realizar observaciones más profundas para conocer mejor cómo se articula la actividad de los capacitadores con las representaciones, y la actividad de los alumnos con las prescripciones. Una dificultad referida por los capacitadores de todos los programas es la de interpretar el programa de estudio y determinar y hacer aplicar las reglas. Hacen lo mejor que pueden con sus conocimientos y experiencias, en función de las reglas explícitas definidas por el colegio (por ej., las relacionadas con los desplazamientos de seguros, con el uso de equipos de protección individual en los talleres) y las reglas en general implícitas del colectivo (por ej., el umbral de tolerancia para el uso de calzado de seguridad en los períodos fuera del taller). La aplicación de las reglas es evaluada de manera dicotómica con la nota de Éxito o Fracaso (igual que las otras competencias). No hay espacio para un reconocimiento del proceso o de la situación de trabajo.

\section{DISCUSIÓN} formación y el aprendizaje, y más precisamente de la actividad de los capacitadores y de los educandos (entre ellos, los referidos por Lacomblez et al., 2006). Nuestra contribución más específica para la reflexión en el marco del último simposio mixto Ergonomic Analysis of Work and Training y Gender and Work (congreso de la Asociación Internacional de Ergonomía, 2009), se inscribía en el eje "Situaciones de capacitación y de aprendizaje específicas de algunas poblaciones, en particular, las mujeres". Un análisis ergonómico de la actividad según el sexo/género ha permitido aportar los conocimientos pertinentes para contribuir a la evolución de la situación de alumnas y alumnos en los diversos programas de estudio. La combinación de métodos y el entrecruzamiento de datos sobre las representaciones de los diversos grupos de actores, sobre el análisis de la actividad y de las condiciones de aprendizaje, y sobre las prescripciones ministeriales han permitido captar algo de la dinámica y de la problemática referente a la SST de los alumnos. A los fines de la discusión, tomaremos en cuenta los siguientes aspectos.

El análisis de las representaciones de los grupos de actores y de los documentos del Ministerio denota un enfoque comportamental y prescriptivo de la SST. La SST es abordada como un conocimiento general de aplicación de reglas que se supone protegen de los riesgos físicos generados por la tarea y por los individuos (malas posturas, no respetar las reglas). Este enfoque se manifestaría principalmente a través de saber ser y de saber hacer de aplicación de reglas y de control de sí mismo. Apunta sobre todo a la transmisión de informaciones sobre la SST y sobre el control de comportamientos individuales. El programa de estudio de ESA introduce una dimensión 
de análisis de los riesgos en el medioambiente pero los alumnos no recuerdan haber aprendido algo sobre ese tema, lo cual no significa que eso sea exactamente así. Aunque la mayoría de ellos haya tomado conocimiento de los derechos y responsabilidades de los trabajadores y empleadores en el curso de SST, pocos alumnos recuerdan que el empleador tiene la obligación de hacer prevención en origen, y que ellos mismos tienen el deber de participar. Al abordar el confort y la seguridad del cliente en las secciones de SST, el programa de estudio de PEL introduce una confusión persistente acerca de quién es la persona a la que se refiere la SST. Para las alumnas, entonces, la SST es ante todo proteger al cliente, y luego prestar atención a sus propias posturas. La relación de servicio no es abordada como un vínculo dinámico en el que el cliente podría ser visto como un par en una relación de cooperación (Falzon \& Lapeyrière, 1998). Evidentemente, la SST no es considerada como una dinámica colectiva con los otros alumnos, futuros colegas de trabajo (Delgoulet \& Vidal-Gomel, 2013). Hasta donde sabemos, las capacitaciones en SST, aun las universitarias, tratan poco esta dimensión que, sin embargo, brinda un margen de maniobra para actuar en prevención. Según las entrevistas realizadas con los capacitadores, el único aspecto de sus experiencias en materia de SST que tienen la oportunidad de platicar es el de la definición y aplicación de reglas con los alumnos, porque estas son fuente de tensión entre los docentes. Vale la pena mencionar que pocos docentes, del conjunto de los participantes, habían seguido alguna capacitación relacionada con la SST. aprendizaje, más emerge otra faceta de la SST, la de los riesgos que provienen de las tareas y los medioambientes. Y cuando observamos más de cerca la actividad en los talleres, nos damos cuenta de que la organización de las actividades puede acentuar los riesgos con el mantenimiento prolongado de posturas estáticas y la cantidad elevada de movimientos repetidos sin pausas suficientes. Aunque el riesgo cero no existe, la situación estudiada está muy alejada de ese ideal, sobre todo en PEL. En particular, los problemas músculo esqueléticos afectan mucho a las alumnas. Estos resultados nos recuerdan que, en el mercado de trabajo, las mujeres están más aquejadas que los hombres por los trastornos músculo esqueléticos, dado el tipo de trabajo que efectúan, las fuertes exigencias posturales y la alta repetición de gestos (Stock et al., 2013, 2008; Vézina et al., 2011).

Todos los alumnos entrevistados se dicen conscientes de la importancia de la SST, pero como este es justamente el tema de la investigación, pueden haber acentuado la 
expresión de su interés en la temática. En cambio, ellos expresan otras inquietudes que merecen ser escuchadas con especial atención: la diferencia percibida entre el colegio y el medio de trabajo en el caso de los alumnos de ESA, la degradación progresiva de su salud en el de las alumnas de PEL, y la confrontación con la discriminación de las alumnas en programas predominantemente masculinos. En efecto, las alumnas de PEL se preocupan por su capacidad de permanecer en el oficio. Es posible que los dolores se disipen con la adaptación y la experiencia, pero nuestros resultados nos inducen a pensar que puede haber alumnos que dejen el colegio con afecciones crónicas: 1) los dolores persistentes o recurrentes que ellas refieren se corresponden con zonas corporales dolorosas en las capacitadoras (Chatigny et al., 2011), en relación con su práctica del oficio; 2) en el salón-escuela, las alumnas aprenden en condiciones parecidas a las condiciones de los salones de peluquería: atención al cliente, trabajo de pie prolongado con brazos en elevación, repetición de gestos, equipamiento poco ajustable y averiado, pocas pausas; 3) el peso de la prevención recae sobre las trabajadoras, ya que la formación no las prepara para actuar sobre las condiciones. Estas situaciones no son ajenas a los escasos medios de los que disponen las trabajadoras de este sector no sindicalizado y no prioritario según la ley de prevención en SST, a la invisibilidad social de la temática de SST en los oficios tradicionalmente femeninos, y a una pobre evolución tecnológica que, de otro modo, obligaría a la escuela a invertir en renovación de equipamiento. Para los alumnos de ESA, la cultura de estos oficios tan masculinos podría limitar la transferencia de los aprendizajes escolares (Chatigny et al, 2000). Aun si los capacitadores y capacitadoras conocen una parte de estas realidades, los alumnos no parecen encontrar eco a sus preocupaciones y se sienten impotentes. Aunque sus actividades profesionales paralelas al colegio puedan también ser en parte responsables por el estado de salud de estos jóvenes (Laberge et al., 2011), las condiciones observadas en el centro de capacitación son fuente de riesgos a nivel músculo esquelético.

\section{Cuestiones de género}

Un problema de género profesional aparece aquí en lo que hace a los "componentes interpersonales de la actividad subjetiva", las "convenciones de acción" en los colectivos (Clot \& Faïta, 2000, p. 9, 13). Para los hombres, esto se refleja en el rechazo a utilizar equipamiento de elevación y protecciones individuales, así como a establecer cooperaciones que les permitirían reducir riesgos en la manipulación de objetos. Los resultados presentados revelan también otra cuestión de género, la de los vínculos sociales de sexo determinados por la cultura, la educación y las instituciones (Messing et al., 2003). Estas dos problemáticas se superponen, tal como lo presentan Clot y Faïta. Los colectivos masculinos del sector de la construcción (sector en el cual se encuentra ESA) le rinden culto a la fuerza bruta y protegen esta herencia en detrimento de la salud de los propios hombres menos robustos y de las mujeres. Estas prácticas se acompañan a menudo de gestos y palabras que favorecen la discriminación y las represalias contra los colegas diferentes (acoso, aislamiento, agresión verbal y/o sexual) (CIAFT, 2011; Couture et al., 2004; Chatigny, 2009), creando situaciones de vulnerabilidad, negación de riesgos y de sus efectos nocivos, y favoreciendo la pasividad frente a la SST. En cuanto al plano de las representaciones, subrayamos la importancia de deconstruir las siguientes ideas: que el trabajo en los sectores femeninos es más fácil y no tiene consecuencias importantes para la salud, que la protección de las máquinas en los sectores masculinos es suficiente para prevenir los riesgos para la salud, que los deterioros progresivos de la salud no merecen ser 
declarados, que la SST debe ser padecida y que el respeto de las reglas de SST implica una falta de virilidad. resultados en coloquios que reúnen delegados sindicales, autoridades y capacitadores. Actualmente participamos, en calidad de invitados por el MELS y la CSST, en dos mesas de concertación: una para elaborar un marco de referencia para el aprendizaje de la SST en los programas de enseñanza técnica colegiada; y la otra para elaborar una estrategia de intervención ante las universidades de Quebec para lograr integrar la SST en la formación de docentes para la enseñanza profesional. Estos dos pedidos interrogan la capacitación y permiten que nos planteemos un relevamiento de los conocimientos de capacitadores y alumnos en materia de SST, y un enriquecimiento del enfoque preventivo. Un desafío importante, consiste en permitir que los alumnos desarrollen no solamente sus conocimientos sobre la SST y reflejos individuales de protección, sino que también aprendan a distinguir los indicadores precoces de deterioro de su salud y a transformarse en actores de la prevención colectiva. Para esto habría que mejorar el proceso de diseño de los programas con la ayuda de un verdadero análisis de la actividad de trabajo, ya que el enfoque del Ministerio se limita a un análisis de la situación. Además, se requeriría disponer de otras investigaciones, en colaboración con investigadores en didáctica profesional, para estudiar las actividades de enseñanza-aprendizaje de la SST en los talleres.

Un proyecto de desarrollo despunta por el lado de las condiciones de la enseñanza y el aprendizaje en los centros de formación profesional. Una comisión escolar que agrupa a varios CFP, que participaba en un encuentro de presentación de resultados, organizado por la Fédération des commissions scolaires (FSC), nos ha invitado a conversar con su comité de SST. Por otro lado, un proyecto paritario (patronal-sindical) sobre la salud psicológica se desarrolla en este momento en un CFP. La CS involucrada ha propuesto luego dos pasantías para estudiantes de la Maestría profesional en Ergonomía. Por último, en el CFP que participó en nuestro estudio, el plan de acción anual incluye ahora proyectos de acción que apuntan también a los programas predominantemente femeninos. 


\section{(1)} los enfoques y roles de los actores clave de la SST frente a la SST de los alumnos, 3) equidad en los enfoques y esfuerzos de prevención, y 4) rol del medio escolar en el aprendizaje de la prevención en origen. En primer lugar, la SST de los alumnos, la de los docentes, la enseñanza y el aprendizaje de la SST se influencian mutuamente. Aun si no es posible producir un desarrollo simultáneo en todas estas áreas, es importante no abordarlas de manera aislada. Por ejemplo, la SST de los alumnos es esencial para la actividad de los capacitadores, quienes se preocupan a menudo por la salud de sus alumnos y se confrontan con diversas prescripciones. Las alumnas de PEL se preocupan al ver a sus capacitadoras afectadas por trastornos músculo esqueléticos. Los docentes recuerdan las reglas y planifican de la mejor manera posible para minimizar los riesgos. Estas actividades, a su vez, están ligadas a la gestión de la SST, especialmente a las políticas y reglas de SST definidas por el colegio, y a las inversiones en materia de equipos y acondicionamiento. En segundo lugar, cada grupo de actores entrevistado tiene un determinado conocimiento de la situación de los alumnos, pero los enfoques y las intervenciones no están concertadas ni son necesariamente coherentes entre sí. La síntesis de los relatos y las observaciones revela una falta de conocimiento de lo que hacen los demás y una falta de coherencia de los enfoques en SST dentro de la escuela y de los programas. En tercer lugar, hemos advertido que un conjunto de recursos y limitaciones tiene influencia en el desarrollo de la salud y de las competencias, de diferente modo según el programa de estudio de que se trate. Algunos condicionantes están vinculados con las particularidades de los oficios involucrados, las tareas y exigencias asociadas, y la evolución de la tecnología en el caso de ESA. Otros condicionantes más macro, de orden cultural, económico y, influencian los enfoques y el abordaje de la SST de las alumnas y los alumnos, así como las representaciones, condiciones de aprendizaje, y roles vinculados a su salud. Es importante entonces demorarse en estas diferencias para dar una mejor respuesta a las necesidades de todo el alumnado. Dada la recurrencia de las dificultades sufridas por las mujeres en trayectorias no tradicionales y a la gravedad de los agravios a su integridad física y psicológica, es urgente avanzar en este tema [7]. Hemos iniciado la preparación de un proyecto de investigación, que favorece la integración y la permanencia de las mujeres en empleos predominantemente masculinos. El equipo de investigación apunta a la inter disciplina entre la ergonomía, la comunicación y la administración de organizaciones. Por último, es menester debatir la misión del medio escolar frente a la SST, como lo proponen Frigul y Thébaud-Mony (2010). ¿El establecimiento escolar tiene su papel bien asumido y dispone de los medios para operacionalizarlo y articularlo con el del entorno laboral? ¿Su misión pedagógica le hace olvidar otros aprendizajes necesarios para la capacitación profesional?

91 Acabamos de terminar una herramienta para los centros de capacitación profesional (Chatigny \& Tondoux, 2014) [8] que tal vez permita introducir un enfoque integrador para los cuatro aspectos mencionados más arriba. La herramienta ha sido elaborada en relación con las líneas de trabajo propuestas por los actores. Incluye una sección de divulgación de los resultados de la investigación sobre las cuatro dimensiones estudiadas (figura 1) y una guía de preguntas para realizar un pre diagnóstico de la situación en el CFP. En la sección SST de los alumnos, las preguntas suscitan 
especialmente la revisión de los incidentes y los dolores experimentados, y el papel de los alumnos en las actividades de prevención.

Los límites de este estudio

Este estudio de casos supone ciertos límites debido a la escasa cantidad de participantes, establecimientos escolares y programas de estudio. Será necesario entonces efectuar estudios longitudinales para completar y validar los resultados con otros programas y centros de formación. Del mismo modo, las preguntas que apenas empezamos a plantear son aquellas que tienen que ver con el lugar de la SST en las actividades de enseñanza y aprendizaje, su articulación con las experiencias de los capacitadores y de los alumnos, y con las representaciones y las prácticas de los entornos laborales que reciben pasantes. El análisis ergonómico que compare los dispositivos y prácticas más o menos evolucionados en un mismo programa de estudios pero en establecimientos diferentes permitiría tal vez definir modelos de desarrollo durable. Asimismo, un análisis conjunto desde la ergonomía y la didáctica profesional sería también muy útil, tal como lo demuestra la reciente investigación de Vidal-Gomel et al. (2014).

\section{BIBLIOGRAFÍA}

Chatigny, C. (2009, septembre). Santé et maintien des femmes en emplois dits traditionnellement masculins. Actes du $44^{\mathrm{e}}$ congrès de la Société d'Ergonomie de Langue Française, Toulouse.

Chatigny, C., Balleux, A., Martin, M., \& Grenier, J. (2005). Apprentissage des tâches et prévention des troubles musculo-squelettiques: dynamiques de formation en santé et sécurité au travail dans trois entreprises du secteur avicole (R-464). Montréal, Québec : IRSST.

Chatigny C., Hastey, P., Riel, J., \& Nadon, L. (2011, mars). Le travail enseignant en centre de formation professionnelle et la santé et sécurité : plusieurs enjeux interreliés. Communication au colloque : Le travail enseignant au XXIe siècle, Lyon.

Chatigny, C., Messing, K., Laperrière, E., \& Thibault, M-C. (2005). Battle fatigue: Identifying stressors that affect counsellors in women's shelters. Canadian Woman Studies, 24(1), 139-144.

Chatigny, C., Nadon-Vézina, L., Riel, J., Couture, V., \& Hastey, P. (2012). Analyse ergonomique de la santé et la sécurité au travail en centre de formation professionnelle. Rapport soumis à l'IRSST (R-756). Repéré à http://www.irsst.qc.ca/-publication-irsst-analyse-ergonomique-de-la-sante-et-de-lasecurite-en-centre-de-formation-professionnelle-r-756.html

Chatigny, C., \& Tondoux, A. (2014). La santé et la sécurité du travail dans les centres de formation professionnelle. La prévention, un projet collectif(RF-802). Montréal, Québec : IRSST.

Clot, Y., \& Faïta, D. (2000). Genres et styles en analyse du travail. Concepts et méthodes, Travailler, $4,7-42$.

Commission de la santé et de la sécurité du travail du Québec (2005). Formation professionnelle et technique. Mieux intégrer les compétences en santé et en sécurité au travail: une mission prioritaire! Repéré à http://www.csst.qc.ca/publications/800/Documents/dc_800_212.pdf 
Conseil d'intervention pour l'accès des femmes au travail (CIAFT) (2011). La mixité au travail, un défi d'égalité. Rapport de la stratégie nationale concertée : pour en finir avec la division sexuelle du travail.

Couture, V., Thibault, M-C., Chatigny, C., \& Messing, K. (2004). Faire fondre le plafond de verre des femmes dans les emplois non-traditionnels. Rapport soumis au Service de la condition féminine de la FTQ. Montréal, Québec : CINBIOSE.

Delgoulet, C., \& Vidal-Gomel, C. (2013). Le développement des compétences : une condition pour la construction de la santé et de la performance au travail. Dans P. Falzon (éd.), Ergonomie constructive. (p. 19-32). Paris, France : PUF.

Falzon, P., \& Lapeyrière, S. (1998). L'usager et l'opérateur : Ergonomie et relations de service. Le Travail Humain, 61 (1), 69-90.

Frigul, N., \& Thébaud-Mony, A. (2010). Où mène le Bac pro ?. Paris, France : L'Harmattan.

Girard, S.A, Doyon P., Gilbert, L., Legris, M., \& Laliberté, D. (2006). Santé et sécurité du travail et formation professionnelle : Prochaine cible d'intérêt. PISTES, 8 (2).

Grossmann, S., Roiné, C., \& Chatigny, C. (2014). Horizons, seuils et passages - L'orientation, l'accès et le maintien des élèves en formation professionnelle à Montréal. Rapport pour Éducation-Montréal.

Laberge, M. (2011). Accueil et intégration sécuritaire et compétente en emploi des élèves inscrits à la formation menant à un métier semi-spécialisé du parcours de formation axée sur l'emploi (Thèse de doctorat). Université du Québec à Montréal.

Laberge, L., Ledoux, E, Thuilier, C., Gaudreault, M., Martin, J.S., Cloutier, E., Auclair, J., Lachance, L., Veillette, S., Rozon, C., Arbour, N., Bescou, S., Agenais, T., \& Hostiou, L. (2011). Santé et sécurité des étudiants qui occupent un emploi durant l'année scolaire - Les effets du cumul d'activités et de contraintes de travail (R-705), Montréal, Québec : IRSST.

Lacomblez, M., Bellemare, M., Chatigny, C., Delgoulet, C., Re, A., Trudel, L., \& Vasconcelos, R. (2006). Ergonomic analysis of work activity and training: basic paradigm, evolutions and challenges. Dans R. Pikaar, E. Konongsveld et P. Settels (Eds.). Meeting Diversity in Ergonomics. Paris, France : Elsevier Ltd.

Ledoux, E., \& Laberge, M. (2006). Bilan et perspectives de recherche sur la SST des jeunes travailleurs (R-481), Montréal, Québec : IRSST.

Leplat, J. (1997). Regards sur l'activité en situation de travail. Paris : PUF.

Messing, K. (1999). La pertinence de tenir compte du sexe des «opérateurs» dans les études ergonomiques : Bilan de recherches, PISTES, 1 (1).

Messing, K., \& Chatigny, C. (2004). Travail et genre. Dans P. Falzon (éd.), Traité d'ergonomie (p. 301-316). Paris, France : Presses universitaires de France.

Messing, K., \& Seifert, A.M. (2001). « On est là toutes seules». Contraintes et stratégies des femmes en contrat à durée déterminé dans l'enseignement des adultes, Travailler, 7, 147-166.

Messing, K., Punnett, L., Bond, M., Alexanderson, K., Pyle, J., Zahm,S., Wegman, D., Stock, S., \& De Grosbois, S. (2003). Be the Fairest of Them All: Challenges and Recommendations for the Treatment of Gender in Occupational Health Research, American Journal of Industrial Medicine, 43, 618-629.

Messing, K., Chatigny, C., \& Courville, J. (1998). « Light » and « heavy » work in the housekeeping service of a hospital. Applied Ergonomics, 29(6), 451-459. 
Messing, K., \& Stelmann, J.M. (2006). Sex, gender and health: the importance of considering mechanism, Environmental Research, 10(2), 149-62.

McDiarmid, M.A., \& Gucer, P.W. (2001). The "GRAS" status of women's work. Journal of Occupational and Environmental Medicine, 43(8), 665-9.

Ministère de l'éducation. (1999). Coiffeuses et coiffeurs, coiffeuses-stylistes et coiffeurs-stylistes, Analyse de situation de travail, Québec.

Ministère de l'éducation. (2000). Électromécanique de systèmes automatisés, Analyse de situation de travail, Québec.

Ministère de l'éducation. (2001). Coiffure, Programme d'études, Québec.

Ministère de l'éducation. (2004). Électromécanique de systèmes automatisés, Programme d'études, Québec.

Ministère de l'Éducation, du Loisir et du Sport du Québec (MELS). (2008). La formation professionnelle et technique au Québec - un aperçu. Repéré à http://www3.mels.gouv.qc.ca/fpt/ Bibliotheque/17-9828.pdf

Ministère du Travail du Québec. (2001). Rapport interministériel sur le harcèlement psychologique au travail. Repéré à http://www.travail.gouv.qc.ca/actualite/harcelement_psychologique/ comite_hpsy.pdf

Ouellet, S. (2009). Acquisition d'habiletés motrices à la découpe de viande et prévention des troubles musculo-squelettiques : apport de l'analyse ergonomique à la conception de formations (Thèse de doctorat). Université du Québec à Montréal.

Ouellet, S., \& Vézina, N. (2005). Du formateur au contenu de formation: Quand la connaissance de la variabilité des méthodes s'impose pour prévenir les troubles musculo-squelettiques. Actes du 36e Congrès annuel de l'Association Canadienne d'Ergonomie, Halifax, 1-5.

Ouellet, S., \& Vézina, N. (2009). Savoirs professionnels et prévention des TMS : portrait de leur transmission durant la formation et perspectives d'intervention. PISTES 11(2).

Ouellette, R. (2008). Statistiques de l'éducation : enseignement primaire, secondaire, collégiale et universitaire. Québec: Ministère de l'Éducation, du Loisir et du Sport.

Paillé, P., \& Mucchielli, A. (2003). L'analyse qualitative en sciences humaines et sociales. Paris: Armand Colin.

Pratte, L. (2008). L'accompagnement de l'élève féminine en stage de formation professionnelle dans un métier traditionnellement masculin (Mémoire de maîtrise). Université de Sherbrooke.

Prévost, J., \& Messing, K. (2001). Stratégies de conciliation d'un horaire de travail variable avec des responsabilités familiales. Le Travail humain, 64, 119-143.

Riel, J. (2009). Analyse de l'activité de travail des enseignantes et enseignants du secondaire (Mémoire de maîtrise). Université du Québec à Montréal.

Riel, J., \& Messing, K. (2011). Counting the minutes : Administrative control of work schedule and time management of secondary school teachers in Québec. Work, 40(1), 59-70.

Seifert, A.M., \& Messing, K. (2007). Understanding women's work: steps toward transformationan introduction, New Solutions: A Journal of Occupational and Environmental Health Policy, 17(1-2), 53-56.

Stock, S., Duguay, P., Lippel, K., Messing, K., Turcot, A., Asselin, P., Prévost J., Turcot, A., Funes, A., \& Traore, I. (2008, juin). Quels sont les travailleurs à risque de troubles musculo-squelettiques? Une 
analyse différenciée selon le sexe des cas de TMS indemnisés par la CSST de 2000 à 2002. 2e Congrès francophone sur les troubles musculo-squelettiques, Montréal.

Stock, S., Nicolakakis, N., Messing, K., Turcot, A., \&t Raiq, H. (2013). Quelle est la relation entre les troubles musculo-squelettiques (TMS) liés au travail et les facteurs psychosociaux ? PISTES, 15(2).

St-Vincent, M., Vézina, N., Bellemare, M., Denis, D., Ledoux, É., \& Imbeau, D. (2011). L'intervention en ergonomie. Montréal, IRSST / Ste-Foy: Éditions Multi Mondes.

Teiger, C. (1993). Représentations du travail, travail de la représentation. In A. Weill-Fassina, P. Rabardel \& D. Dubois (dir.), Représentations pour l'action (pp. 311-344). Toulouse : Octarès.

Vézina, M., Stock, S., Funes, A., Delisle, A., St-Vincent, M., Turcot, A., \& Messing, K. (2011). Description de l'environnement organisationnel et des contraintes physiques à l'emploi principal. In Enquête québécoise sur des conditions de travail, d'emploi, de santé et de sécurité du travail (EQCOTESST ) (pp. 233-322), Institut national de santé publique du Québec et Institut de la statistique du Québec - Institut de recherche Robert-Sauvé en santé et sécurité du travail (R-691).

Vidal-Gomel, C., Delgoulet, C., \& Geoffroy, C. (2014). Compétences collectives et formation à la conduite d'engins de secours dans un contexte de spécialisation des sapeurs-pompiers en France. Laboreal, 10(1).

\section{NOTAS}

1. Un oficio se considera no tradicional cuando las mujeres o los hombres están representados en él en menos de 33\% (1/3). Por ejemplo, en América del Norte, la peluquería es un oficio tradicionalmente femenino y la carnicería, tradicionalmente masculino. (p. 8).

2. Vézina, M., E. Cloutier, S. Stock, K. Lippel, É. Fortin et autres (2011). Rapport sommaire. Enquête québécoise sur des conditions de travail, d'emploi, et de santé et de sécurité du travail (EQCOTESST). Québec, Institut de recherche Robert-Sauvé en santé et sécurité du travail, Institut national de santé publique du Québec et Institut de la statistique du Québec. Repéré à http:// www.irsst.qc.ca/-publication-irsst-enquete-quebecoise-conditions-travail-emploi-sst-eqcotesstsommaire-rr-691.html (le 19 août 2014).

3. Este protocolo ha sido presentado por el Comité international pour l'Éducation et la Formation à la Prévention de l'Association Internationale de la Sécurité Sociale (AISS) -Comité internacional para la Educación y la Formación en Prevención de la Asociación Internacional de Seguridad Social- en el 2e Séminaire international Enseignement en santé-sécurité au travail (2do Seminario internacional de Enseñanza en salud-seguridad en el trabajo), realizado en Quebec en 2003. Los siguientes países han adherido: Alemania, Brasil, Canadá (Quebec), España, Estados Unidos, Francia, Portugal, Reino Unido, Suiza. Hemos iniciado una investigación en Francia y Portugal para inventariar las iniciativas que se desprenden de este acuerdo. Hasta ahora no se ha encontrado ninguna.

4. Ledoux y Laberge (2006), en su reseña sobre los estudios relativos a la SST de los trabajadores jóvenes han identificado diversas hipótesis para explicar la gravedad de las lesiones. Se trata no solamente de factores como la falta de madurez y el sentimiento de invulnerabilidad, sino también de condiciones de trabajo que sobre exponen a los jóvenes, como la falta de formación y de guía, o la atribución de tareas pesadas que los de más edad ya no quieren o no pueden hacer.

5. Catherine Delgoulet, LATI - Université Paris Descartes /CREAPT; Marta Santos, Faculté de psychologie, Université de Porto; Hélène Veyrac, Université de Toulouse, École Nationale de Formation Agronomique

6. Procedimiento de poner bajo llave las fuentes de energía provenientes de los equipos para realizar sin riesgo una tarea de mantenimiento, por ejemplo. 
7. Se ha creado una coalición social para trabajar en la integración y el sostén de las mujeres en los oficios de la construcción:http://www.newswire.ca/en/story/1089183/la-coalitionquebecoise-pour-les-femmes-dans-la-construction-interpelle-le-gouvernement-pour-mettre-enplace-des-mesures-contraignantes-pour-l-acces-e (sitio consultado el 19 de agosto de 2014).

8. http://www.irsst.qc.ca/-publication-irsst-centres-formation-professionnelle-rf-802.html (sitio consultado el 19 de agosto de 2014).

\section{RESÚMENES}

El objetivo de esta investigación ha sido estudiar las problemáticas de la salud y seguridad en el trabajo (SST), y entre ellas la de los alumnos, en centros de formación profesional. Se han empleado diversos métodos con 76 participantes (dirección, profesionales, docentes, alumnos): entrevistas individuales y colectivas, cuestionarios auto administrados, observaciones, análisis de materiales educativos sobre SST. Estos han permitido estudiar las experiencias de SST, las prescripciones, los enfoques, los roles y los factores que influencian las representaciones y el aprendizaje. Los alumnos (20) provenían principalmente de las formaciones en Peluquería y en Electromecánica de sistemas automatizados (19). Los resultados revelan que los distintos grupos de actores tienen representaciones diferentes, que los alumnos están más preocupados por su SST de lo que creen sus capacitadores, cuáles son los daños a la salud que se producen, y que estos ocurren con mayor frecuencia en los alumnos de Peluquería, y cuáles son las perspectivas de género en SST. La discusión abarca el enfoque y los métodos de investigación, los enfoques en SST, las intervenciones que se desprenden de esta investigación y los aspectos a desarrollar.

O objetivo desta investigação foi o de estudar as problemáticas de saúde e segurança no trabalho (SST) em centros de formação profissional, isto é, a SST dos estudantes. Métodos diversificados foram mobilizados junto de 76 participantes (direção, profissionais, formadores, estudantes): entrevistas individuais e coletivas, questionários autoadministrados, observações, análise de documentos relativos ao ensino da SST. Estes permitiram estudar as experiências de SST, as prescrições, os enfoques, os papéis e os fatores que influenciam as representações e as aprendizagens. Os estudantes (20) provinham maioritariamente de formações em Cabeleireiro e Eletromecânica de sistemas automatizados (19). Os resultados revelam representações diferentes segundo o grupo de atores, estudantes mais preocupados com a sua SST do que o pensavam os seus interlocutores, danos para a sua saúde mais numerosos nos estudantes de cabeleireiro, abordagens de género relativamente à SST. A discussão remete para os métodos e abordagens da pesquisa, para as abordagens de SST, as intervenções resultantes da investigação e os aspetos a desenvolver.

L'objectif de cette recherche était d'étudier les problématiques de santé et de sécurité du travail (SST) en centre de formation professionnelle, dont la SST des élèves. Plusieurs méthodes ont été mobilisées auprès des 76 participants (direction, professionnels, enseignants, élèves): entretiens individuels et collectifs, questionnaires auto administrés, observations, analyse de documents pour l'enseignement de la SST. Elles ont permis d'étudier les expériences de SST, les prescriptions, les approches, les rôles et les facteurs qui influencent les représentations et les apprentissages. Les élèves (20) provenaient principalement de Coiffure et d'Électromécanique de 
systèmes automatisés (19). Les résultats révèlent des représentations différentes selon les groupes d'acteurs, des élèves plus préoccupés par leur SST que ne le pensent leurs intervenants, des atteintes à leur santé, plus nombreuses chez les élèves en coiffure, des approches genrées de la SST. La discussion ouvre sur les méthodes et l'approche de recherche, les approches de SST, les interventions découlant de la recherche et les aspects à développer.

The goal of this research was to study the health and safety issues at work in vocational training centers. 76 participants (managers, professionals, vocational trainers and students) went through a process of individual and collective interviews, self-administered questionnaires and observation. An analysis of documents on health and safety was also performed. This allowed us to study the experiences surrounding health and safety at work, prescriptions about activities, approaches, roles and factors affecting representations and learning. Students were mainly from Hairdressing (20) and Automated Systems Electromechanics (19) courses. The results show different representations depending on the group of actors. Some students were more worried about their health and safety at work than perceived. Health damage was more frequent for hairdressing students. There were also gender approaches on health and safety at work. The discussion focuses on research methods and approaches, HSW approaches, interventions resulting from the research and elements in need of further development.

\section{ÍNDICE}

Palabras claves: formación profesional, aprendizaje de salud y seguridad, peluquería, electromecánica, análisis ergonómico según el sexo/género

Keywords: vocational training, learning in health and safety, hairdressing, mechanics, ergonomic analysis according to sex/gender

Palavras-chave: Formação profissional, aprendizagem em saúde e segurança, cabeleireiro, eletromecânica, análise ergonómica em função do sexo/género

Mots-clés: formation professionnelle, apprentissage en santé et sécurité, coiffure, électromécanique, analyse ergonomique selon le sexe/genre

\section{AUTORES}

\section{CÉLINE CHATIGNY}

Université du Québec à Montréal (UQAM), Département d'éducation et formation spécialisées, Centre de recherche interdisciplinaire sur le bien-être, la santé et l'environnement (CINBIOSE). C.P. 8888. Succ. Centre-ville, Montréal (Québec), Canada, H3C 3P8

chatigny.celine@uqam.ca

\section{JESSICA RIEL}

Université du Québec en Outaouais, Département de relations industrielles, Centre de recherche interdisciplinaire sur le bien-être, la santé et l'environnement (CINBIOSE)

jessica.riel@uqo.ca 